\title{
Do Private Regulations Ratchet Up?: How to Distinguish Types of Regulatory Stringency and Patterns of Change*
}

\author{
Devin Judge-Lord \\ University of Wisconsin-Madison \\ Benjamin Cashore \\ Yale University \\ Constance L. McDermott
Oxford University
}

February 10, 2020

Due to inconsistent concepts of regulatory stringency, scholars offer conflicting accounts about whether competing private governance initiatives "race to the bottom," "ratchet up," "converge," or "diverge." To remedy this, we offer a framework for more systematic comparisons across programs and over time. We distinguish three often-conflated measures of stringency: regulatory scope, prescriptiveness, and performance levels. Applying this framework, we compare competing U.S. forestry certification programs, one founded by environmental activists and their allies, the other by the national industry association. We find 'upwardly divergent' policy prescriptiveness: both programs increased in prescriptiveness, but this increase was greater for the activist-backed program. Furthermore, requirements added by the activist-backed program were more likely to impose costs on firms than requirements added by the industry-backed program, many of which may even benefit firms. These results are consistent with the hypothesis that industry-backed programs emphasize less costly types of stringency than activistbacked programs. They also reveal patterns of change that previous scholarship failed to anticipate, illustrating how disentangling types of stringency can improve theory building and testing.

*In Organization \& Environment 2020 Special Issue on Social Movements and Private Environmental Governance. We thank two anonymous reviewers and the editor for comments that greatly improved this analysis. We are also grateful for feedback from participants at conferences, including the 2018 American Politics Workshop at the University of Wisconsin-Madison, the 2016 Association of Public Policy Analysis and Management (APPAM) Annual Research Conference, and the 2015 Association of Environmental Studies and Sciences Annual Meeting. We are also grateful for extensive feedback on a 2014 draft of the analytic framework and empirical application, from officials with the Forest Stewardship Council (FSC), the Sustainable Forestry Initiative (SFI), and the Program for the Endorsement of Forest Certification (PEFC). This research was made possible by funding from the Fox Foundation, Procter \& Gamble, Staples, Office Depot, and Arup. We also thank Erica Pohnan, Akiva Fishman, Shaan Amin, and Evan Ramzipoor for research and editing assistance. The authors are fully responsible for data collection, analysis, and any errors. 
Keywords: policy change, private authority, certification, corporate social responsibility, private governance 


\section{INTRODUCTION}

Private governance initiatives, such as product certification programs, have targeted farm and factory working conditions, greenhouse gas emissions, and fishery, mining, and forest management (Auld, 2014; Bartley, 2003; Bozzi et al., 2012; Hudson and Hudson, 2003; van der Ven, 2015; Vince and Haward, 2017). Many of these programs were founded by activists who were dissatisfied with public regulations. Activists use tactics such as boycotts as "sticks" and brand-boosting praise as "carrots" to pressure companies to comply with certification programs that often exceed the requirements of public laws (Cashore, 2002). When companies agree to add certification requirements to their purchasing policies and contracts, those certification programs gain the power to regulate how commodities are produced. Industry groups often resist these efforts at private (i.e., non-state) regulation, in some cases launching competing certification programs to offer more "business-friendly" alternatives.

Public debates among supporters of activist-backed programs and industry-backed alternatives often center on the relative stringency of each program's regulatory requirements. The perceived stringency of a program's requirements is often central to both positive and negative evaluations of legitimacy among stakeholders, both those a program aims to empower and those it aims to regulate. ${ }^{1}$ That is, whether activists endorse a product certification program, whether buyers demand products certified by that program, and sellers' decisions to comply with that program's requirements depend on each actor's perceptions of the program's stringency. Public claims about stringency are part of a process through which competing programs gain or lose stakeholder support, market power, and thus policymaking authority (Bartley, 2007; Bodansky, 1999; Cashore, 2002).

Concepts of regulatory stringency are also at the center of conflicting theoretical and empirical claims from scholars across political science, economics, and sociology concerning the likely effects and future trajectories of private regulations. A key motivation behind this research is to assess whether the social and market forces that shape private regulations lead 
to patterns similar to those observed in public regulations, such as a "race to the bottom" as governments or programs try to attract firms with less stringent regulations, a "race to the middle" as shared expectations emerge, or a "race to the top" as companies operating in areas with more stringent regulations lobby to equalize requirements across jurisdictions (Berger and Dore, 1996; Vogel, 1995). While public policy scholars have spent a great deal of effort developing concepts of regulatory stringency and policy change needed to assess these hypotheses (Green-Pedersen, 2007; Hall, 1993; Howlett and Cashore, 2014), private governance scholarship gives much less attention to measuring policy change or regulatory stringency. This limited attention has led to seemingly contradictory empirical findings and hindered theory development and testing about how and why private regulations change.

As noted by Brunel and Levinson (2016) and Howlett and Cashore (2007), concepts of stringency in existing work tend to be either insufficiently precise to be consistently applied across programs, insufficiently comprehensive to yield consistent results, or completely absent.

To address this gap, we build on taxonomies from the public policy literature to offer a two-part framework to describe and compare regulations over time. Part one distinguishes three types of regulatory stringency: 1) How comprehensive is the scope of issues addressed? 2) How prescriptive are the requirements? 3) What are the specific levels of performance required? Part two offers a method to classify changes across programs, yielding nine possible patterns to describe both relative and absolute directions of policy change. This approach provides a common terminology to describe how various regulations in the same policy space may change over time. Such a systematic framework is especially critical where complex regulatory standards contain many different social, environmental, and economic requirements. It also clarifies debates where programs backed by different coalitions develop alternative standards and compete for legitimacy and regulatory authority.

We proceed in the following steps. Section two maps the different concepts and measures of regulatory stringency in existing private governance scholarship. Section three details our framework for measuring regulatory stringency. Section four applies the framework to 
compare competing certification programs in the U.S. forestry sector, arguably one of the most institutionalized areas of private regulation. Section five discusses the implications of our results and outlines future research questions emerging from our findings.

\section{Regulatory Stringency as a VARiable}

Though concepts of regulatory stringency are often poorly defined, they are critical to a wide array of scholarship. Concepts of regulatory stringency are required to test theories about how policy content shapes activist support, market adoption, social or ecological impacts, and how other programs respond (i.e., theories where regulatory requirements are an explanatory variable). Similarly, concepts of regulatory stringency are required to assess how activist campaigns, market forces, and competition among programs affect policy development and content (i.e., theories where regulatory requirements are the dependent variable).

Stringency as an explanatory variable: Scholars who study how private regulations gain legitimacy, trust, or support from various audiences posit that regulatory stringency influences these outcomes. For example, McDermott (2012) argues that stringency may reduce trust by mandating formulaic, top-down approaches. Perceived stringency may increase market demand for certified products (Atkinson and Rosenthal, 2014) but may also reduce adoption by firms (Prado, 2013). Alternatively, perceived stringency may increase adoption as companies anticipate potential public reactions to their choices (Bullock and van der Ven, 2018). Changes in stringency that disadvantage some firms or groups may catalyze these actors to create alternative private regulatory programs (Meidinger, 2003). Alternatively, those disadvantaged by changes to private regulation may then opt to pursue their aims through public policy (Weimer, 2006). Such outcomes would be consistent with broader findings from scholarship on

"corporate social responsibility" (CSR) initiatives, such as environmental management systems (EMS), industry codes of conduct, and third-party certification programs, which find that more costly requirements are less likely to be adopted (Delmas and Montiel, 2008; Kollman and Prakash, 2001; Lyon and Maxwell, 2008). Firms will only adopt costly requirements if 
there is a countervailing benefit of certification, whether an abstract "social license to operate" or a concrete benefit like market access or a price premium. In contrast, firms will adopt practices that benefit them regardless of countervailing benefits.

The effects of stringency on trust, legitimacy, compliance cost, and adoption matter because anticipating the impact of private regulations "on the ground" requires understanding their evolutionary trajectories (van der Ven et al., 2018). These are complex empirical questions. Even activist-backed programs that establish stringent requirements on one issue at one time may not do so on other issues and at other times (LeBaron and Burgoon, 2018). Nuanced gaps or "loopholes" in otherwise stringent private regulations may explain their lack of success in addressing problems such as deforestation (van der Ven et al., 2018). Furthermore, private regulatory requirements may interact with public policies that shape and constrain their impact (Bartley, 2018). Together, these theories emphasize how regulatory stringency affects the adoption of and support for private governance initiatives as well as their potential to address social and ecological problems.

Stringency as a dependent variable: Regulatory stringency is a main dependent variable in theories that explain how ideological, economic, political, and social forces work to shape and constrain policy content over time (Bartley, 2003; Cashore et al., 2004; Fischer and Lyon, 2014).

Differing ideas about the political responsibilities of businesses shape both activist demands for private governance and firms' responses to private governance efforts (Bartley, 2003; Djelic and Etchanchu, 2017). These different ideas are then embodied in more or less stringent policies depending on which coalitions gain rulemaking authority (Botzem and Dobusch, 2012; Hsueh and Prakash, 2012). For example, Bartley (2003) finds private regulations emerging when social movements target companies with tactics that aim to redirect, rather than challenge, neo-liberal ideas about the central role of businesses in society. Green (2013) finds private authority filling regulatory voids where demand for rules is not met by the supply of public policy. Others find private regulations arising from collective action by industry 
to preempt or replace more stringent government regulations (Bartley, 2007; Cashore, 2002; Grabosky, 2013; Loconto and Fouilleux, 2014; Lyon and Maxwell, 2008; Maxwell et al., 2000; Prakash, 2000). Abbott and Snidal (2009) suggest that the content of public and private regulations is a joint result of bargaining between activists and firms. The common thread is that each of these studies aims to explain relative differences or changes in policy content.

Others seek to explain variation in regulatory stringency as a result of endogenous interactions among private authorities (DeLeon and Rivera, 2009; Eberlein et al., 2014; Green, 2017; Gulbrandsen, 2014; Howard-Grenville et al., 2008; Li and van 't Veld, 2015; Mills, 2016). For example, Smith and Fischlein (2010) suggest that competing private regulations will change frequently and often imitate each other. Similarly, Eberlein et al. (2014) identify "frequent rule revision" or "differentiation among rule systems" as potential effects of such interaction.

A related body of scholarship seeks to explain regulatory stringency as a result of strategic interactions among the coalitions backing competing programs. Some focus on how competition may lead to more "weak or lax standards" as firms "shop" for lower-cost programs, potentially causing a "race to the bottom" (Abbott and Snidal, 2010; Fransen, 2011; Gulbrandsen, 2004). In contrast, others find competition causing "weak" regulations to be "revised upwards" as activists invite public comparisons with the requirements of "higher" regulations (Overdevest, 2005, 2010). And still others find that either pattern might occur, depending on market and industry structures (Cashore et al., 2004; Hassel, 2008; van der Ven, 2015). Cashore et al. (2004) highlight how market and institutional logics initially pressure coalitions to "lower" stringency but later work to maintain differences.

Concepts of regulatory stringency are also at the core of formal models of private governance. Theories suggest that standards may increase or decrease stringency under different conditions, such as increases or decreases in compliance costs or market demand (Abderrazak and Youssef, 2009; Fischer and Lyon, 2014). Formal models (Fischer and Lyon, 2014; Li and van 't Veld, 2015; Poret, 2016) and empirical research (Cashore et al., 2004) both suggest 
that asymmetric incentives lead competing programs to adopt different levels of stringency in equilibrium. Where an activist-backed regulation competes with an industry-backed regulation, these theories predict that the activist-backed program will end up being more stringent.

While these theories offer logical hypotheses, efforts to assess them have been hindered by inadequate attention to the dependent variable they seek to explain. The result is contradictory findings, especially regarding patterns of change. Some posit - and find evidence for - a pattern where competing regulations "ratchet up" with less stringent regulations converging toward more stringent ones (Overdevest, 2005, 2010; Overdevest and Zeitlin, 2014). Others positand find evidence for - the exact opposite pattern, in which competitive pressures lead to a "race to the bottom" with more stringent programs decreasing stringency and converging toward less stringent ones in (Abbott and Snidal, 2010; Fransen, 2011; Gulbrandsen, 2004). Still others posit - and find evidence for-yet another pattern where programs maintain different levels of stringency, that is, they remain distinct, neither converging to the "top" nor the "bottom" (Cashore et al., 2004). While these three sets of findings seem incompatible, we argue that they are the result of different measurement strategies. Reconciling them thus requires a set of shared concepts and measures of regulatory stringency.

\subsection{Concepts \& Measurement of Variation in Private Regulations}

The diversity of private governance scholars' conceptual and empirical approaches to measuring regulatory stringency makes this literature vibrant but confusing: Some scholars evoke vertical notions of variation, describing standards as high or low or more or less stringent (Fischer and Lyon, 2014; Li and van 't Veld, 2015). Others evoke horizontal notions of variation, describing the width or breadth of issues covered (Auld, 2014; Heyes and Martin, 2017). Cashore (1997) calls attention to variation in flexibility versus prescriptiveness, the extent to which regulations use mandatory and substantive performance thresholds. Others measure high and low stringency in a relative sense, defining a "benchmark" standard against which 
others are measured (Overdevest, 2005, 2010). Still others combine concepts of breadth and prescriptiveness into a broader notion of stringency (Fransen, 2011). These distinct dimensions of stringency are often overlooked or conflated. For example, formal models often assign each program a single overall "quality" or "stringency" parameter that could be measured in multiple ways yielding different empirical results. And these are only a few of the many measures of stringency used in this literature, ranging from approaches so broad that they conflate many of these concepts, to so narrow that they measure only a few select components of just one (see Table 1).

In the absence of consistent measures of regulatory stringency, scholars have turned to proxy measures. For example, Darnall et al. (2010) consider a program's sponsor to be a signal of its stringency. In the broadest study to date, van der Ven (2015) uses another common proxy for stringency-compliance with perceived "best practices," often considered "benchmarks" for measuring stringency but based on a variety of different notions of "rigor" and "credibility." As a result, these approaches cannot examine relationships between stringency and program sponsorship or between stringency and perceived stringency.

More importantly, inconsistent approaches to measuring regulatory stringency prevent us from adjudicating among claims that competing programs will "race to the bottom," "ratchet up," "converge," or "diverge." Indeed, different measurement strategies explain the seemly contradictory evidence in favor of each theory. While van der Ven (2015) does find support for the prediction that activist-backed private regulations are more likely to align with "best practices," he does not find support for the prediction that industry-backed regulations are less likely to do so. The latter finding seems to contradict findings by Cashore et al. (2004) that industry-backed programs set less stringent requirements. However, this is due to differences in measurement; Cashore et al. focus on the prescriptiveness of substantive regulatory requirements, while van der Ven focuses on stakeholder engagement and other forms of procedural "best practices"- - two distinct notions of stringency.

Two common challenges have hindered efforts to identify patterns of policy change. First, 
Table 1: Concepts and Measures of Regulatory Stringency

\begin{tabular}{|c|c|c|}
\hline Selected Scholarship & Concept (arranged narrow to broad) & Measurement orientation \\
\hline $\begin{array}{l}\text { García-Montiel et al. } \\
\text { (2017) }\end{array}$ & $\begin{array}{l}\text { "more rigorous," "higher level," "higher quality,", } \\
\text { and thus "Greater complexity/Effectiveness/Cost" } \\
\text { vs. "More Simplicity/Lower Cost" }\end{array}$ & $\begin{array}{l}\text { Number of indicators. De- } \\
\text { scriptions of consistency, co- } \\
\text { herence, and completeness. }\end{array}$ \\
\hline Moore et al. (2012) & Management practices changed & $\begin{array}{l}\text { Survey of self-reported num- } \\
\text { ber and type of practices im- } \\
\text { plemented }\end{array}$ \\
\hline $\begin{array}{l}\text { McDermott et al. } \\
(2010)\end{array}$ & "comprehensiveness and prescriptiv & $\begin{array}{l}\text { Number of key issues with } \\
\text { most prescriptive language }\end{array}$ \\
\hline $\begin{array}{l}\text { Overdevest } \\
\text { Zeitlin }(2014)\end{array}$ & "far apart" or "closer" on select "Characteristics" & $\begin{array}{l}\text { Binary table of select issues } \\
\text { and descriptive examples }\end{array}$ \\
\hline Overdevest (2010) & $\begin{array}{l}\text { "comparative quality"--weaker" are "revised up- } \\
\text { wards" to be "equivalent" to "higher and more } \\
\text { prescriptive standards" }\end{array}$ & $\begin{array}{l}\text { Descriptive theory, examples, } \\
\text { and review of previous com- } \\
\text { parisons }\end{array}$ \\
\hline Fransen (2011) & $\begin{array}{l}\text { "stringency" as "comprehensive in scope, specific in } \\
\text { content, and prescriptive in terms of requirements" }\end{array}$ & $\begin{array}{l}\text { Description based on "leading } \\
\text { policy analysts per issue area" }\end{array}$ \\
\hline Hansen et al. (2006) & $\begin{array}{l}\text { Select "general features" and "six aspects" of man- } \\
\text { agement }\end{array}$ & $\begin{array}{l}\text { Descriptive table of select is- } \\
\text { sues }\end{array}$ \\
\hline Auld (2014) & $\begin{array}{l}\text { "Policy scope and regulatory domain," "policy } \\
\text { changes," "character of the rules developed" }\end{array}$ & $\begin{array}{l}\text { Description of the set of prob- } \\
\text { lems addressed and how }\end{array}$ \\
\hline Cashore et al. (2004) & "stringency" & Descriptive theory, examples \\
\hline $\begin{array}{l}\text { Smith and Fischlein } \\
(2010)\end{array}$ & $\begin{array}{l}\text { "stringency" of "weightings across multiple, and } \\
\text { often conflicting, attributes," also "excellence in } \\
\text { content" }\end{array}$ & examples \\
\hline Porter (2014) & "hard law" or "soft law" & Descriptive \\
\hline Gulbrandsen (2004) & $\begin{array}{l}\text { "variations in the strength": "more stringent } \\
\text { and less discretionary," "more rigorous and wide- } \\
\text { ranging" vs. "weak or lax" with "wider flexibil- } \\
\text { ity" Some "regulations have become more flexible" } \\
\text { while others are "changing upward" }\end{array}$ & Desc \\
\hline Eberlein et al. (2014) & $\begin{array}{l}\text { "differentiation" along "dimensions of regulatory } \\
\text { governance," e.g. "more or less stringent" or "reg- } \\
\text { ulatory capacity" }\end{array}$ & $\begin{array}{l}\text { Descriptive typology, exam- } \\
\text { ples }\end{array}$ \\
\hline Hassel (2008) & $\begin{array}{l}\text { "high and low quality regulation," "higher stan- } \\
\text { dards" vs. "lower standards" }\end{array}$ & Descriptive theory, examples \\
\hline Bartley (2003) & "more credible claims" vs. "lax standards" & Descriptive theory, examples \\
\hline $\begin{array}{l}\text { Abbott and Snidal } \\
(2009)\end{array}$ & $\begin{array}{l}\text { "regulatory outcomes"-"stringent" "higher stan- } \\
\text { dards" vs. "less stringent" "business-friendly" } \\
\text { "weaker standards" }\end{array}$ & Descriptive theory \\
\hline $\begin{array}{ll}\text { Bernstein } & \text { and } \\
\text { Cashore }(2007) & \end{array}$ & $\begin{array}{l}\text { Pressure to "raise" or "lower" requirements "ex- } \\
\text { plains convergence/ divergence" }\end{array}$ & Descriptiv \\
\hline $\begin{array}{l}\text { Kollman and Prakash } \\
\text { (2001), Potoski and } \\
\text { Prakash (2005) }\end{array}$ & $\begin{array}{l}\text { "lax" or "processes-based" vs. "more stringent" } \\
\text { "outcome-based" or "product-based" "types of reg- } \\
\text { ulations" }\end{array}$ & $\begin{array}{l}\text { ISO14001 classified as process- } \\
\text { based, stringency assessed } \\
\text { only for public regulations }\end{array}$ \\
\hline $\begin{array}{l}\text { Prakash and Potoski } \\
(2007)\end{array}$ & "stringent" vs. "lenient" & $\begin{array}{l}\text { Costs, social externalities, and } \\
\text { branding benefits }\end{array}$ \\
\hline Formal models & "sustainability quality level" (Poret, 2016), & Costs vs. benefits to programs \\
\hline $\begin{array}{l}\text { of "stringency" or } \\
\text { "quality" }\end{array}$ & $\begin{array}{l}\text { "stricter rules" (Schmitz et al., 2017), "stringency" } \\
\text { (Fischer and Lyon, 2014) }\end{array}$ & $\&$ firms \\
\hline $\begin{array}{l}\text { Formal models of is- } \\
\text { sue scope }\end{array}$ & $\begin{array}{l}\text { "issue-width" in an "issue space" (Hayes \& Martin } \\
\text { 2015) }\end{array}$ & $\begin{array}{l}\text { Costs vs. benefits to pro } \\
\text { and funders }\end{array}$ \\
\hline
\end{tabular}


results vary depending on the policy components studied. Even the handful of scholars who have developed direct and precise measures of stringency (the top of Table 1) tend to only focus on a few salient components, rather than attempting to assess the entire range of requirements that regulations address. This approach can lead to conflicting results if scholars select different policy components as indicators of stringency. For example, to compare forestry certification programs, Cashore et al. (2004) assess prescriptiveness on seven issues related to ecological protection (restrictions on the use of plantation forestry, chemicals, clearcuts, exotics, reserves, streamside riparian zones, and genetically modified organisms) and find large enduring differences between activist-backed and industry-backed programs. In contrast, Overdevest and Zeitlin (2014) compare these same programs on six other features-two substantive requirements on firm behavior (public reporting and stakeholder consultation), two on compliance mechanisms (auditing and supply chain tracking), and another two on decision-making and marketing strategy —and find that these programs "all moved closer." Here, different measurement strategies led to different conclusions that then supported conflicting theories of policy change.

Second, binary indicators such as whether or not a program addresses a given topic-that is "is this issue in the program's scope?"- fail to capture variation in degree-that is, "how high is the threshold set" (e.g., what is the required frequency of public reporting or prohibited amount of pollution?) and "how prescriptive are they?" (How much is voluntary versus mandatory?). The scope of requirements, degree of prescriptiveness, and levels of thresholds are each important dimensions of variation but may exhibit different patterns of change. For example, Overdevest and Zeitlin (2014) assert that the industry-backed program moved in the direction of the activist-backed program within the scope of issues related to public reporting and consultation, while Cashore et al. (2004) found that these competing programs did not converge in prescriptiveness on issues related to ecological protection. The apparent conflicts between Overdevest and Zeitlin's study and Cashore et al.'s study are thus largely resolved by distinguishing findings about the scope of issues covered versus the prescriptiveness of 
regulatory requirements.

If selection and measurement decisions explain variation in findings, methods that allow more systematic comparisons are the remedy. To address this need, we offer a framework to (1) measure three types of stringency and (2) characterize change over time.

\section{A Framework to Measure Regulatory Stringency and Change}

The first step for scholars who wish to make claims about stringency involves describing policy content according to policy settings, scope, and prescriptiveness (Table 2). Comparing across programs or over time requires a second step: measuring relative stringency and change on each dimension (Table 4). First, we elaborate on step one.

\subsection{Step 1: Measuring Scope, Prescriptiveness, And Policy Settings}

We focus on three dimensions of variation: (1) the comprehensiveness of a regulation's scope (i.e., which policy problems it addresses), (2) the extent to which requirements are prescriptive versus flexible (i.e., whether they have mandatory and substantive thresholds), and (3) the levels of those thresholds or similarly specific policy settings. Our framework thus combines qualitative issue-by-issue comparison of policy settings with two measurement concepts-policy scope and policy prescriptiveness-that can be applied across issue areas and thus aggregated to measure overall stringency (see Table 2). That is, by comparing the number of issues covered by each regulation and the number of prescriptive requirements on those issues, scholars can assess aggregate trends.

Scope: Because each program may cover a different set of issues at a given point in time, assessing the relative scope of issues they address requires inductively deriving a full range

of policy issues addressed by one or more regulatory texts in a given policy domain. Any comparison of regulatory scope across policies depends (often implicitly) on the set of issues 
Table 2: Types of Regulatory Stringency

\begin{tabular}{|c|c|c|}
\hline & Program Level & Issue Level \\
\hline $\begin{array}{l}\text { Policy } \\
\text { Ends }\end{array}$ & $\begin{array}{l}\text { How comprehensive is the scope of } \\
\text { issues addressed? }\end{array}$ & $\begin{array}{l}\text { What are the specific requirements } \\
\text { (i.e. policy settings) on each issue? } \\
\text { (e.g. the specific size of stream buffer } \\
\text { zones) }\end{array}$ \\
\hline $\begin{array}{l}\text { Policy } \\
\text { Means }\end{array}$ & $\begin{array}{l}\text { In aggregate, across all issues, how } \\
\text { prescriptive is each regulation? To } \\
\text { what extent (e.g. on what portion of } \\
\text { issues) are there mandatory and } \\
\text { substantive thresholds? }\end{array}$ & $\begin{array}{l}\text { 1. How prescriptive is each } \\
\text { requirement? } \\
2 . \text { How are requirements enforeced?* } \\
\text { (*Beyond the scope of this paper) }\end{array}$ \\
\hline
\end{tabular}

that the researcher uses as the "denominator" in the portion issues addressed by each program. Scholars often give too little attention to this set of relevant comparisons given its importance to any conclusion about policy scope. Once a researcher establishes a comprehensive set of issues, they can assess the extent to which each regulation covers this set of issues. ${ }^{2}$ With the measurement concept of issue scope, one can assess a regulation's absolute requirements (i.e., how many key issues it addresses); its relative requirements (i.e., how many more or fewer issues it addresses than its competitor), and in change over time (i.e., how many changes occurred between Time 1 and Time 2).

Prescriptiveness: Second, this framework calls on researchers to measure the extent to which each requirement has substantive and mandatory features such as performance thresholds (see Table 3 adapted from Cashore (1997)). In forestry, thresholds may include the maximum size of clearcuts allowed or the minimum buffer zones required around streams. Because "prescriptive versus flexible" is about how each issue is addressed (whether a regulation has mandatory thresholds), not the ends of the policy (the levels of those thresholds), one can compare prescriptiveness across substantive requirements.

Prescriptiveness is a continuum. Discretionary guidelines, practices, processes, or plans are the least prescriptive because they allow maximum flexibility. Procedural requirements that prescribe processes that companies must follow but not outcomes are somewhat prescriptive, 
Table 3: Prescriptiveness of Policy Types

\begin{tabular}{llc} 
& \multicolumn{1}{c}{ Discretionary } & Non-discretionary \\
\cline { 2 - 3 } Procedural (plan- or systems-based) & Flexible & Somewhat prescriptive \\
\cline { 2 - 3 } Substantive (e.g. a policy threshold) & Flexible & Most prescriptive \\
\cline { 2 - 3 } &
\end{tabular}

but substantive requirements are more prescriptive. Mandatory substantive requirements require precise actions and outcomes, such as quantitative performance thresholds, not merely a process that may yield varying results. Compared with mandatory performance thresholds, requirements to follow local "best management practices" are less prescriptive because these practices may not include substantive requirements.

On each issue, the first step is to identify both absolute and relative measures of prescriptiveness. At any point in time, a comparison across programs can yield three possibilities: "no prescriptive requirements," "some prescriptive requirements," or "most prescriptive" (requiring as much as or more than any other regulation). Coding prescriptiveness across issues thus creates an additional measure of policy scope: How many key issues have at least "some prescriptive requirements?" Coding prescriptiveness across programs creates a measure of the relative level of prescriptive requirements in aggregate. Additionally, our framework classifies changes as becoming more prescriptive or less prescriptive on each issue, thus capturing the direction of change in prescriptiveness.

Policy Settings: Finally, the third type of stringency-specific performance levels (what policy scholars call "policy settings") — captures the substance of policy requirements on each key issue. For example, forestry regulations have different requirements for how close to streams loggers can harvest. In this example, all standards prescribing minimum noharvest buffers around streams are equally prescriptive since all are mandatory substantive requirements, albeit with different thresholds. Yet the widths of stream buffers and other specific policy settings are a meaningful type of variation. Unfortunately, most specific policy settings, even prescriptive ones, cannot be quantified and are thus difficult to compare or aggregate. Even numeric stream buffer requirements can be difficult to compare because they 
often vary in different contexts-for example, in mountainous or flat areas or whether fish live in the stream (see Figure 5 in section 4). Measurement strategies that allow programlevel aggregation cannot replace issue-specific qualitative comparison. It is crucial to both quantify absolute and relative differences and describe the key differences that capture the overall trends. We thus suggest that scholars combine aggregate measures with descriptive comparisons of important requirements, assessing policy settings on each issue in an absolute sense, in a relative sense (if possible), and in how the required level of performance changed. Stylized Example: At its most stylized, Step 1, comparing two hypothetical programs ("A" and "B") in a policy space with two issues ("Hazardous Chemicals" and "Worker Training") might look like this: A researcher examines regulations in this policy area and inductively identifies two policy issues. Both programs have some requirements on both issues, so they are equal in policy scope. Program A bans using chemicals above quantitative toxicity thresholds. In contrast, Program B bans "hazardous" levels, which auditors could interpret several ways, so Program A is more prescriptive on the issue of Chemicals. For policy settings, the two programs ban slightly different lists of chemicals, so the researcher can only compare their specific requirements on chemicals qualitatively, finding that Program A focuses on ecologically harmful chemicals while program B targets those most harmful to humans. On the second issue, both programs require mandatory worker training programs, and neither specifies how many hours, so they are equally prescriptive on Training. Each program suggests a slightly different list of topics for training to cover. Program A focuses more on skills needed to avoid ecological harm, and Program B focuses more on worker safety, so again, the researcher can only compare their policy settings qualitatively. Yet a pattern emerges: Program A, the overall more prescriptive program, is also more focused on ecological protection. (Perhaps environmental activists have more influence in Program A). In contrast, Program B is more focused on worker safety. (Perhaps decision-making at Program B is more influenced by labor unions or by firms aiming to reduce the risk that injuries at one firm will result in reputational or regulatory costs for the whole industry.) 
To assess change over time, one would use the same process to compare versions of each standard to their previous versions (e.g., Program A version 2.0 to Program A version 1.0).

As this example illustrates, the combination of precise and comprehensive measurement can avoid problems with using any one approach alone. Measuring scope alone risks overlooking variation in prescriptiveness and levels of performance required. Measuring prescriptiveness alone risks capturing a kind of stringency that is void of content. And comparing a few specific performance levels alone risks missing the broader picture, or worse, making overly broad generalizations where a different set of issues would yield different conclusions.

\subsection{Step 2: Classifying Patterns of Change}

Building on Baumgartner (2002) and Howlett and Cashore (2007), Step 2 emphasizes the importance of measuring the direction and pace of policy change. Assessing theorized patterns of change like punctuation or equilibrium requires measuring change on each dimension of stringency because there may be equilibrium on one dimension but punctuation on another. In absolute terms, stringency may be increasing, decreasing, or neither. In relative terms, regulations may be converging, in equilibrium, or diverging on each dimension over any given period (Table 4). Thus, in aggregate, nine relationships fully capture the possible dynamics between two programs on each dimension of change (scope, prescriptiveness, or policy settings). All theories about regulatory stringency (including those from Table 1) should be able to be expressed in terms of the dimension(s) to which the theory applies, the absolute directions of change they predict, and relative relationships they anticipate.

Conclusion: This framework for measuring regulatory stringency helps researchers accomplish several crucial tasks. For example, Brunel and Levinson (2016) argue that a measure of regulatory stringency must: (1) measure change over time, (2) assess both relative and absolute magnitudes, (3) aggregate across multiple issue areas, and (4) be theoretically relatable to compliance costs. To these criteria, we add that any measurement approach should also (5) capture qualitative differences in policy settings. Step 1 of our framework 
Table 4: Possible Patterns of Change in Relative Stringency

Directions of Change

(in comprehensiveness of scope, prescriptiveness, or levels of requirements)

\section{Relationship Among Standards}

\begin{tabular}{|c|c|c|c|}
\hline \multirow{3}{*}{ Increasing } & Converging & Parallel & Diverging \\
\hline & $\rightarrow$ & $\nearrow$ & $\nearrow$ \\
\hline & $\nearrow$ & $\nearrow$ & $\rightarrow$ \\
\hline \multirow{3}{*}{$\begin{array}{l}\text { Opposite or } \\
\text { Equilibrium }\end{array}$} & $\searrow$ & $\longrightarrow$ & $\nearrow$ \\
\hline & $\nearrow$ & $\longrightarrow$ & $\searrow$ \\
\hline & $\searrow$ & $\searrow$ & $\longrightarrow$ \\
\hline Decreasing & $\longrightarrow$ & $\searrow$ & $\searrow$ \\
\hline
\end{tabular}

*The two arrows in each cell represent two programs. A study of three programs would have three arrows.

satisfies these five criteria, and Step 2 goes on to classify relative change over time (a logical extension of the above criteria 1 and 2).

\subsection{Theorizing in Terms of Scope, Prescriptiveness, and Policy Set- TINGS}

Our core methodological critique is that different dimensions of stringency may exhibit different patterns of change. Precise and testable hypotheses about the causes and effects of policy change must distinguish among types of change. If different dimensions of regulatory stringency vary independently, a vast array of theories that use stringency as an explanatory or dependent variable must be revised to specify the dimension(s) to which they apply. Revisiting theories in terms of scope, prescriptiveness, and policy settings may yield different predictions on each dimension. It is beyond the scope of this paper to revisit all hypotheses in this vast literature in light of our methodological critique, but, for illustrative purposes, we offer examples of such restatements required for hypotheses rooted in compliance cost, competition, and program differentiation.

Compliance Costs and Competition: By breaking down stringency into three distinct dimensions, we expand on two related propositions: (1) Compliance costs cause competing programs backed by different coalitions to set different levels of stringency. Specifically, 
Cashore et al. (2004) and Fischer and Lyon (2014) theorize that industry-backed programs set less stringent regulatory requirements than activist-backed programs because industry-backed programs are less willing to impose costs on firms. (2) Programs change in response to changes by their competitors. Specifically, when private authorities compete for market share, if one changes its requirements, the other will change in a similar direction (Fischer and Lyon, 2014; Smith and Fischlein, 2010). Yet, these studies do not specify which dimensions of stringency ought to be affected by compliance costs and competition. Do incentives rooted in compliance cost affect each dimension in the same way? Are competing programs more responsive to changes in the scope, prescriptiveness, or policy settings of competing programs? Disentangling policy settings, scope, and prescriptiveness suggests more precise hypotheses to assess theories rooted in compliance cost and competition.

Revised Compliance Cost Hypotheses: If broadening scope is low-cost for firms, but increasing prescriptiveness and performance levels are high-cost,

H1.1: An industry-backed regulation will be more similar to an activist-backed regulation in policy scope than in prescriptiveness or required performance levels.

H1.2: An industry-backed regulation will be more likely to respond to changes in an activist-backed regulation by converging in policy scope than in prescriptiveness or required performance levels (i.e., policy scope will be less elastic).

Compliance Cost and Differentiation: Another core theoretical claim is that different coalitions will establish qualitatively different policies (Botzem and Dobusch, 2012; Hsueh and Prakash, 2012). By distinguishing types of stringency, we identify qualitative differences in how stringency varies across programs. Specifically, we expect that the relative stringency of an industry-backed program on a given issue will depend on whether the requirements result in net costs or benefits to the industry.

We expect activist-backed programs to target issues where requirements impose costs on firms to achieve social or ecological goals. On these issues, industry-backed programs have 
different incentives; they must balance their need to maintain legitimacy in the eyes of buyers with their need to minimize compliance costs for the industry. The likely result is that an industry-backed program will set a lower level of stringency than that of an activist-backed program, even as they both change over time. We also expect a larger difference between programs on issues where compliance costs are higher or where industry-backed programs can more easily foster an impression of stringency without imposing costly requirements.

The opposite result is likely on issues where industry-wide compliance with requirements would provide net benefits to the industry. Here, activist-backed programs have little incentive to develop stringent requirements because activist pressure is redundant. These "business-friendly" issues are frequently addressed by industry associations. Such issues include coordinating resources and solving collective action problems related to industry reputation (e.g., through public image campaigns) and capacity (e.g., by developing collective goods like technical knowledge or a skilled workforce). By "collective action," we mean actions across individuals or firms that have net benefits but that require a coordinating institution. Like industry associations, regulatory agencies and certification programs can serve as coordinating institutions. Business-friendly certification programs may also attempt to boost perceptions of stringency by adding requirements to do things that firms would do anyway. If observers fail to distinguish among different types of stringency on different issues, such a strategy may be a low-cost and effective way to shape perceptions of overall stringency.

Revised Differentiation Hypotheses: Where activist-backed and industry-backed private regulations compete,

H2.1: Activist-backed regulations will have more comprehensive coverage, more prescriptive requirements, and higher performance thresholds on costly issues.

H2.2: Industry-backed regulations have more comprehensive coverage, more prescriptive requirements, and higher performance thresholds on business-friendly issues, such as those that firms do anyway or those related to industry collective action problems. 
These hypotheses illustrate how scholars could revise many of the theories reviewed in section 2 in light of our methodological critique. One can assess whether doing so is worthwhile in two ways: (1) Does restating theories in terms of the predicted direction of change in scope, prescriptiveness, and policy settings improve our understanding of past research? (2) Does applying the regulatory stringency framework reveal patterns of change that other methods failed to discover? Sections 4 and 5 show that our framework meets both

tests: Applying our framework reveals that the scope, prescriptiveness, and policy settings of forestry certification programs do follow different patterns and that existing theories cannot fully account for these changes.

\section{Competing U.S. Forest Certification Programs}

We illustrate our methods for measuring stringency through an analysis of forestry certification in the United States, one of the most advanced cases of private regulation. As is the case in many policy domains, forestry scholars have carefully dissected components of forestry regulations, both public and private. Yet the unit of analysis in political science scholarship still tends to be broad characterizations of entire policies or only a few of their constituent parts. We draw on domain-specific scholarship to conduct a more systematic analysis. The results of this analysis offer the most comprehensive and detailed description of changes in forestry certification standards to date.

Forest certification illustrates how market-based authority can involve formal decisionmaking modeled on government rulemaking processes, legalistic requirements, and powerful enforcement mechanisms. When product certification programs gain power with buyers and retailers, a timber company's contracts may depend on an audit of their compliance with hundreds of requirements. Noncompliance may be costly. For example, Resolute Forest Products claimed damages of $\$ 100$ million CND related to auditor findings of nonconformance (Tigar, 2017). This scale of impact on the industry makes forest certification an important case. 
For over 20 years, the Forest Stewardship Council (FSC) and Sustainable Forestry Initiative (SFI) have been developing written Forest Management Standards (standards) that promote different concepts of "sustainable" forest management. The SFI and FSC play a significant role in regulating the forest products industry in the United States, regulating a third of commercially harvested timberland, including most corporate-owned timberland (see Figure 1). Many U.S. states support certification as a compliment or alternative to public regulation. For example, some state regulators forgo inspections of FSC-certified forests as legal compliance is part of their FSC audit (Judge-Lord, 2013).

Figure 1: U.S. timberland by ownership and certification scheme
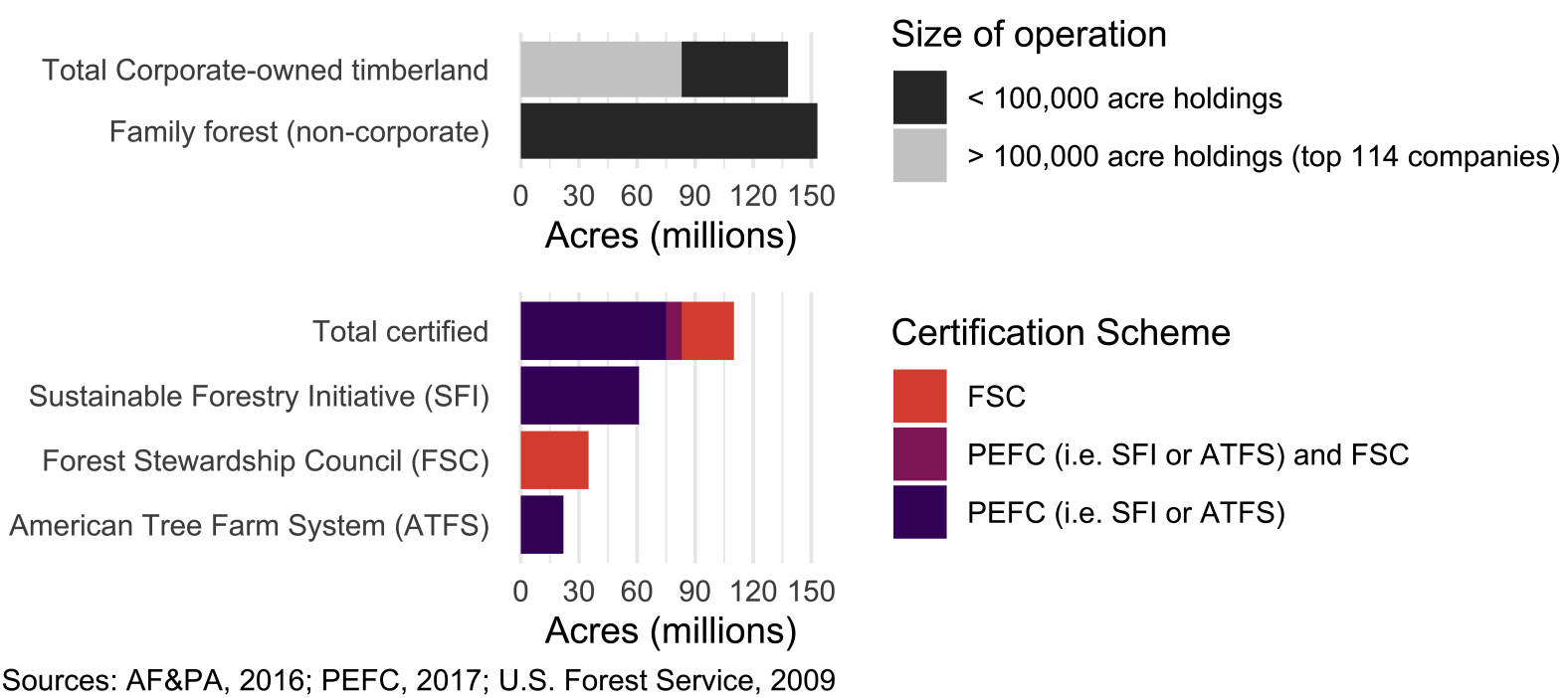

Sources: AF\&PA, 2016; PEFC, 2017; U.S. Forest Service, 2009

Origin of the FSC: The FSC was established as an international nonprofit organization in 1993 by a group of environmental and social advocacy organizations, academics, indigenous groups, and companies. FSC's founders designed its rulemaking procedures as a "democratic" process where members vote on decision-making rules as well as substantive policy (Meidinger, 2003). FSC standards begin with a set of international "Principles and Criteria" (FSC-P\&C) that are used by national-level organizations to develop more specific indicators. Our analysis of the FSC in the United States thus assesses both the international FSC-P\&C and the FSC-US national standard.

Origin of the SFI: In 1995, in response to the growing influence of the FSC, the U.S.- 
based industry association-the American Forest \& Paper Association-established a forest management standard and required its members (most of the U.S. forest products industry) to support it. Optional third-party auditing was added in 1998, which became mandatory in 2002, the same year that the American Forest \& Paper Association made the SFI a legally distinct entity with a formally independent rulemaking process governed by an 18member board of directors. The SFI has since been endorsed by the global Program for the Endorsement of Forest Certification (PEFC). The PEFC maintains a set of Sustainable Forest Management Benchmarks intended to guide participating programs, many of which are industry-backed alternatives to the FSC. Unlike the FSC-P\&C, the PEFC does not require the SFI and other national-level programs to adopt its benchmarks verbatim. Instead, they are expected to demonstrate the "equivalence" of their standards with PEFC benchmarks. Thus, national standards, like the SFI's, can have less stringent requirements than PEFC benchmarks.

"Sustainable" Forestry: As is the case in many policy domains, there are ongoing public debates over acceptable business practices and the appropriate role of public and private regulation in forestry. "Sustainable" forestry has many meanings (McDermott, 2012). For example, some programs use "natural" conditions or functions as benchmarks for sustainability, involving complex choices about what is "natural" and what degree of naturalness is appropriate. In other conceptions, "sustainable" mostly captures the long-term efficiency of production rather than naturalistic management. Such differences lead to different coalitions pursuing "sustainable forestry" to have diverging goals and adopt different means to achieve them. A regulation targeting efficiency may require high levels of utilization of trees and tree-parts. In contrast, a regulation targeting naturalistic management may include requirements to leave economically valuable timber behind for animal habitat or soil health. Disagreements become concrete in the details of regulatory requirements. Thus, a meaningful assessment of similarities and differences between regulations requires attention to detail. 


\subsection{Scope, Prescriptiveness, And Policy Settings in Forestry}

To measure comprehensiveness of scope, we reviewed all FSC, PEFC, and SFI standards in effect between 2008 and 2016. We assessed the coverage of each standard across 48 distinct "key issues," capturing a broad scope of forestry requirements-from employee wages and resource utilization to protections for endangered species and indigenous peoples' rights. These issues were selected in 2008 by McDermott et al. (2010) using an iterative process to disaggregate forestry policies to capture all of the key issues addressed by FSC, PEFC, or SFI requirements.

To measure prescriptiveness, we code the text of each standard that addresses each key issue according to the classification scheme set out in Table 3. If companies have discretion among performance levels, only the least demanding levels can be considered prescriptive. For example, if companies are required to "maintain or enhance" water quality, the option to merely "maintain" means that there is no mandatory requirement to "enhance" water quality.

To measure policy settings, we offer detailed issue-by-issue comparisons of performance requirements on most of our 48 key issues in the text below and all of them in the Supplementary Appendix. This approach is similar to how previous scholars have descriptively compared the SFI and FSC standards on select issues, except with a comprehensive scope of potential issues. Doing so allows us to classify each specific change, the types of issues that changed, and differences among standards on key issues that may be important but not (yet) salient in the public debates.

\section{$4.2 \quad$ Results}

Here we compare each standard to the previous version from the same program and to the contemporary version from its competitor program. Thus, we assess revisions in the FSC- International's 2012 Revised Principles and Criteria 01-001 Version 5-0 (FSC-P\&C) and compare them with revisions in the PEFC's Sustainable Forest Management Standards 1003:2010. Similarly, we compare the 2010 FSC-U.S. Forest Management Standard Version 
1.0 with the FSC-US National Indicators and regional standards it replaced, and we compare both FSC-US standards to the 2005-2009, 2010-2014, and 2015-2019 SFI standards. Unless otherwise specified, "FSC-US" and "SFI" refer to the version of each standard in effect in 2016. We do not fully capture subnational variation. The FSC-US standard recognizes nine different sub-national regions. Some have additional indicators, meaning that, in some states, FSC standards were more prescriptive or had higher performance thresholds than our findings reflect (more on this in the Supplementary Appendix).

\subsubsection{Comparing FSC's and PEFC's International Requirements}

Scope: The FSC-P\&C and PEFC maintained a similar policy scope (see the top panel of Figure 2). The PEFC once covered slightly fewer issues than did the FSC-P\&C, but its 2010 revisions added new requirements on eight key issues that it previously did not address, making the two programs generally aligned in scope. As of 2015, the FSC P\&C covered three potentially costly issues that the PEFC still did not: carbon emissions, restrictions on conversion to plantations, and worker wage requirements (see the middle panel of Figure 2). PEFC covered two issues relating to public relations that FSC-P\&C did not: managing the aesthetic impacts of logging and allowing public access to forests.

Prescriptiveness: Overall, the FSC maintained more prescriptive requirements in its Principles \& Criteria than the PEFC benchmarks (the top panel of Figure 2). Still, the PEFC moved closer to the FSC-P\&C on some key issues (the middle panel of Figure 2). These include additional requirements regarding indigenous rights, community benefits, and public reporting and consultation (see the Supplementary Appendix for the specific language). The PEFC became at least as prescriptive as the FSC-P\&C on over half of key issues. In absolute terms, the PEFC increased prescriptiveness on 18 key issues and decreased on none, whereas the FSC-P\&C increased on 13 and decreased on four. Yet significant differences remained. The FSC-P\&C contained more prescriptive language on most ecological criteria, including protected areas and restrictions on conversion to plantations. 
Both programs had more procedural requirements than substantive requirements (i.e., they are more focused on process than outcomes). Despite convergence in the PEFC's revised requirements, the FSC-P\&C remained more prescriptive than PEFC requirements on 17 of the 48 key issues. PEFC requirements were more prescriptive on nine issues. Both programs being equally prescriptive on 22 issues. Because the PEFC started at a lower level but increased prescriptiveness on more issues than did FSC P\&C, the resulting pattern is an "upward convergence" (the bottom panel of Figure 2).

Policy Settings: One particularly controversial issue is the conversion of natural forests to timber plantations. Both programs permitted certification of forestry plantations that were converted from natural forest under "justifiable circumstances," which differed qualitatively between the two programs. For the FSC, this means that conversion has "clear, substantial, additional, secure, long-term conservation benefits." For the PEFC, it means that conversion must have "long-term conservation, economic, and social benefits." They also differed regarding the extent of forest conversion allowed. The FSC-P\&C allowed companies to convert "limited areas," while the PEFC allows "small proportions of forest types." Both standards specify that conversion must not damage culturally or socially significant areas, but whereas PEFC suggested that forests should only be certified if the conversion occurred before 2011, the FSC-P\&C required that conversion occurred before 1994. These conversion dates are significantly different thresholds.

Both FSC-P\&C and PEFC added new requirements on socioeconomic issues, land tenure rights, and stakeholder consultations. In addition to citing the U.N. Declaration on Rights of Indigenous Peoples, both programs included criteria that require the free, prior and informed consent of indigenous peoples and local communities. The FSC-P\&C required "free and informed consent" concerning control over forest operations and compensation for the use of traditional knowledge. Both standards also recognized legal, traditional, and customary rights. However, the FSC-P\&C were more prescriptive, defining topics on which forest managers must consult with indigenous peoples, while the PEFC standards are more procedural, requiring 
Figure 2: Scope and Prescriptiveness of FSC P\&C and PEFC 2008-2015

\section{Relative Prescriptiveness}

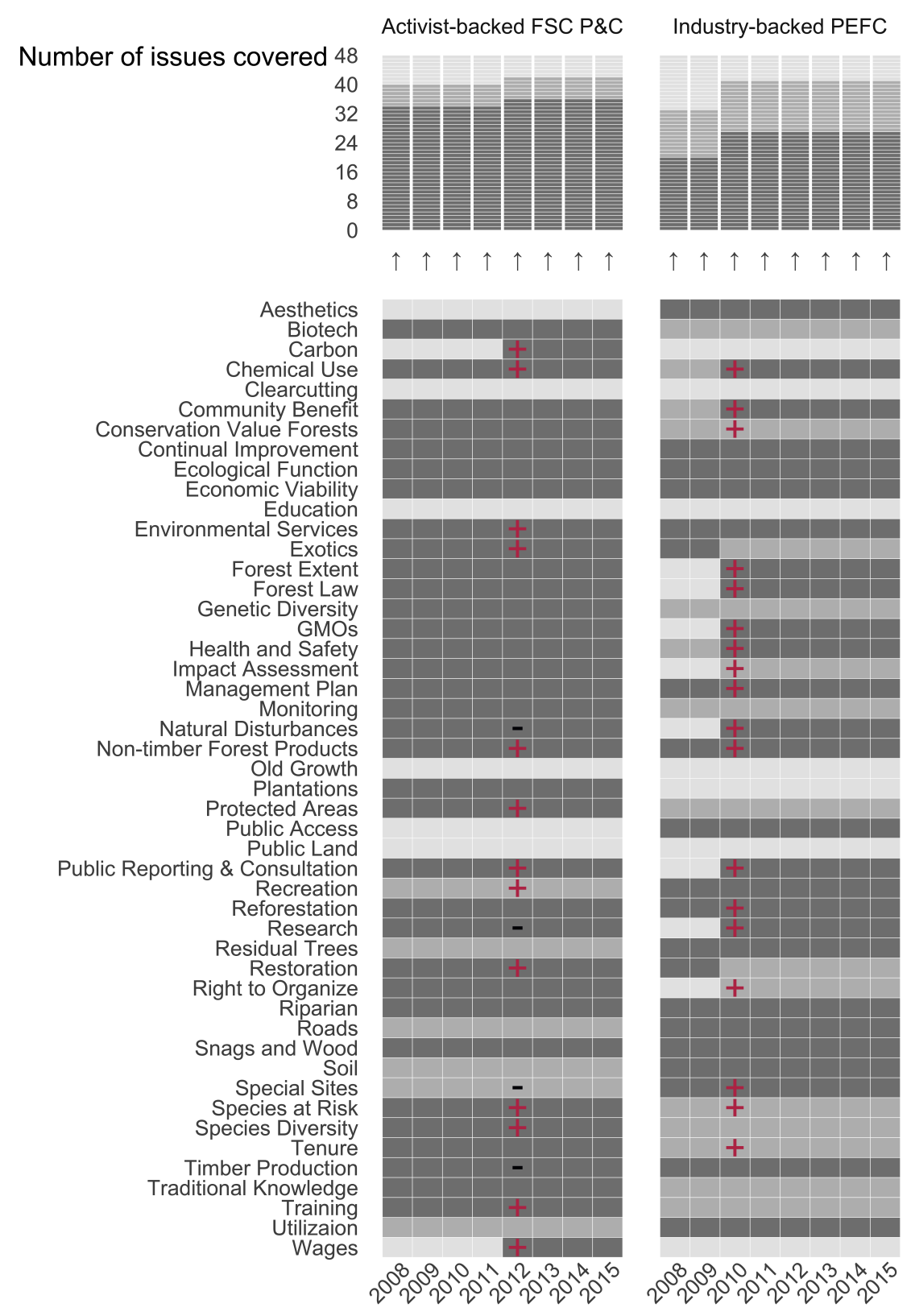

\section{Absolute Change in Prescriptiveness}

Number of issues changed 24

Activist-backed FSC P\&C

16

12

8

4

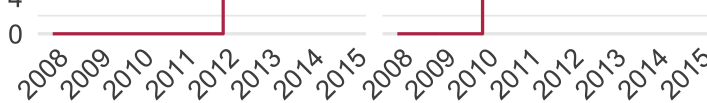

No prescriptive requirements Less prescriptive

Most prescriptive

- Became less prescriptive

+ Became more prescriptive No change 
only that engagement takes place. The FSC's criteria regarding public consultation include special obligations to "affected stakeholders" compared with "interested stakeholders" while PEFC requirements regarding "local people and other stakeholders" are the same.

Both programs covered similar ecological issues, with some qualitative differences. Both FSC-P\&C and PEFC requirements prohibited the use of GMOs in the area being certified, with some possible flexibility should scientific evidence affirm the safety of GMO trees. FSC$\mathrm{P} \& \mathrm{C}$ allowed documented and monitored use of biological control methods but prohibited a specific list of "Highly Hazardous Chemicals." The PEFC added prohibitions on pesticides that remain "biologically active" and "highly toxic" pesticides where viable alternatives are available. The PEFC explicitly required managers to avoid chemicals where they threaten water quality, while FSC-P\&C water protection criteria were less explicit. Both programs had similar requirements for sustainable production of timber and non-timber forest products (NTFPs), but the FSC-P\&C set a higher level of protection for animal habitat. While the FSC-P\&C required protection of rare and threatened species and their habitats, the PEFC only required that protected and endangered species not be exploited for commercial purposes and that managers take measures for their protection "where necessary," without defining these conditions.

Summary: Overall, while the PEFC added more requirements concerning indigenous rights and labor standards and came to cover a similar scope of issues to the FSC P\&C, the FSC-P\&C remained more prescriptive on social issues and significantly more prescriptive on ecological issues. Compared with the prescriptiveness of the FSC-US and SFI described below, the FSC-P\&C and PEFC requirements exhibited more convergence on both scope and prescriptiveness (compare Figures 3 and 4), though many differences in policy settings remained. 


\subsubsection{Comparing the FSC-US and SFI}

Scope: Consistent with the international level, the activist-backed FSC-US program and industry-backed SFI program in the United States address a similar scope of issues, but the FSC-US was more prescriptive on most (the top panel of Figure 3). As of 2016, the FSC-US covered six potentially costly issues that the SFI did not; community benefit requirements, forest extent restrictions, required impact assessments, protected area restrictions, restoration requirements, and indigenous tenure protections (the middle panel of Figure 3). The SFI, in turn, covered one issue that the FSC-US did not: contributing to forestry research. Both programs added requirements on greenhouse gasses in 2010. SFI allowed for the conversion of natural forests to plantations if ecological impacts are not significant and the converted forest type is not rare, but in 2015, SFI added a requirement for companies to conduct an assessment of these impacts. Yet, the FSC-US still maintained more prescriptive requirements, only allowing certification of plantation forests if they were converted from natural forests before 1994. FSC-US also required a portion of these plantations to be maintained as, or restored to, natural conditions.

Prescriptiveness: In 2008, the FSC-US was more prescriptive on 36 of 48 key issues, and the SFI was more prescriptive on five issues. These five are some of the most "business-friendly" issues: continual improvement of management planning, educating the public about forestry, contributions to forestry research, worker training, and efficient material utilization. In 2016, the FSC-US was more prescriptive on 38 key issues, and the SFI was more prescriptive on the same five issues. The two standards were equally prescriptive on five issues. This means that the FSC-US had the "most prescriptive" requirements - those as prescriptive or more than any other program - on 43 issues, and the SFI had the most prescriptive requirements on 10 (the top panel of Figure 3).

Counting changes made to the FSC-US and SFI standards between 2008 and 2016 reveals an "upward diverging" pattern, where the FSC-US became more prescriptive on more issues than did the SFI (the bottom panel of Figure 3). Of 48 key issues, the FSC-US became more 
prescriptive on 21, whereas SFI became more prescriptive on 12 (eight in 2010, one more in 2013, and three more in 2015).

Policy Settings: Issues such as limits on clearcut size and harvesting near streams clearly illustrate enduring differences between the SFI and the FSC-US because we can compare policy settings on these issues both qualitatively and quantitatively. Qualitatively, the FSC-US increasingly restricts the size and shape of clearcuts to reflect "natural disturbance" and maintain ecological functions regardless of how the landscape looks, whereas the SFI emphasizes "the visual impacts of forestry" and requires rapid site "green-up." Quantitatively, the SFI limited clearcuts for all forest types to an average of 120 acres with no maximum and no limits for harvesting with $20 \%$ tree retention (i.e., intensive but not clearcut harvesting). In contrast, the FSC-US limits clearcuts to a 40-acre average and 80-acre maximum, with additional restrictions based on region and forest type. The FSC-US also limits harvesting with $20 \%$ tree retention to a 100 -acre average and 80 -acre maximum, with further restrictions based on region and forest type (Figure 4).

For harvesting near streams, the FSC-US lists specific requirements for water quality, habitat, and other objectives with a focus on restoration. Additionally, most FSC-US regions have numeric minimum riparian buffer zones (Figure 5). In 2015, SFI expanded its definitions of riparian areas but continued to allow more discretion regarding what managers include in plans to protect water resources with no numerical minimum buffers beyond those in state laws and best management practices. While we can only compare most other policy settings qualitatively, the FSC-US clearly requires higher levels of performance on many social and ecological issues (Table 5).

While both the FSC-US and SFI became more prescriptive, they did so to different degrees and in different areas. The SFI's changes in 2010 emphasized issues related to industrial capacity (e.g., worker training requirements) and reputation (e.g., managing the visual impact of harvesting, communicating with stakeholders about logging, and educating the public about forestry), issues where the SFI already had the most prescriptive requirements. Changes 
Figure 3: Scope and Prescriptiveness of FSC-US and SFI 2008-2016

\section{Relative Prescriptiveness}

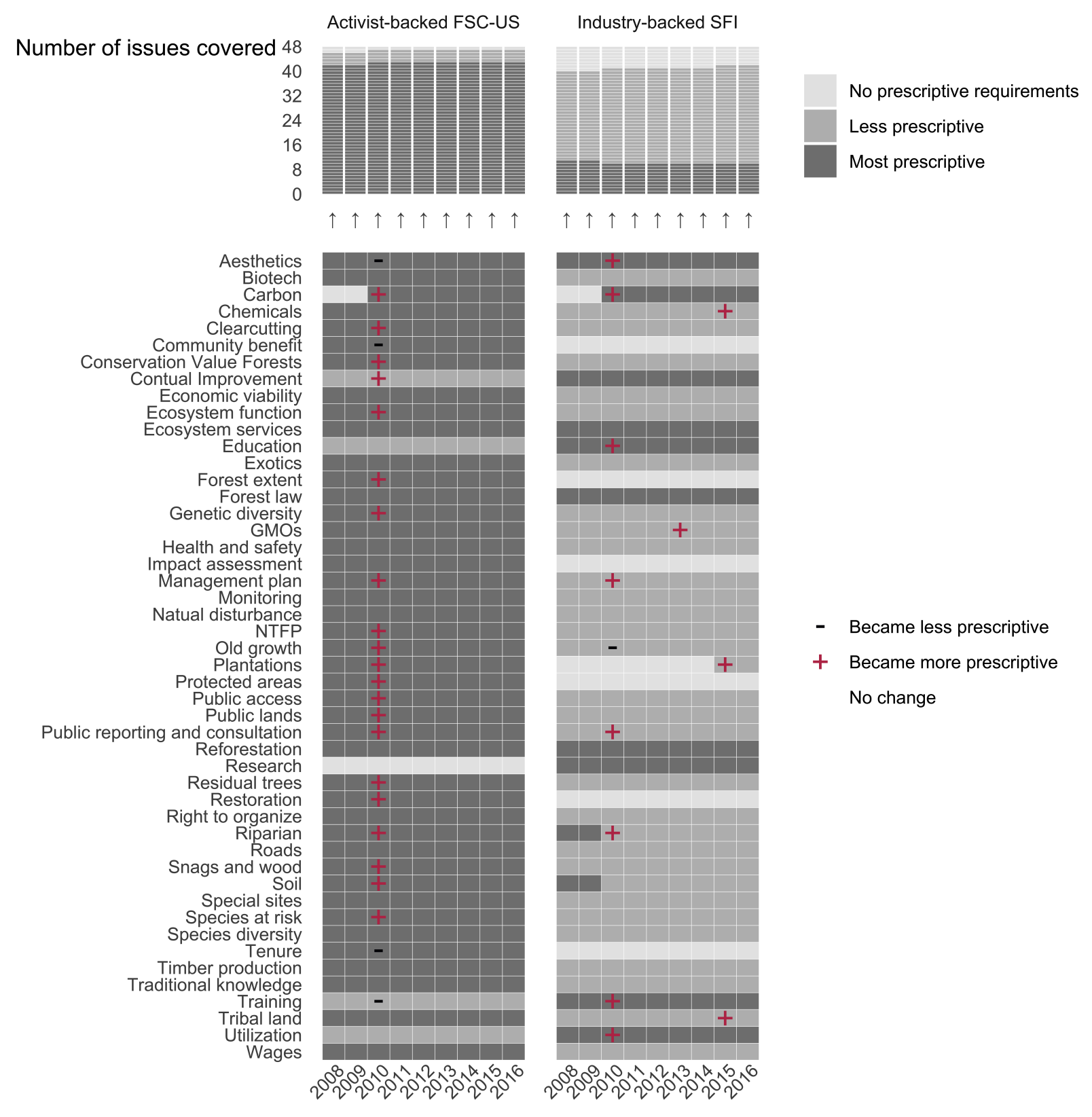

\section{Absolute Change in Prescriptiveness}

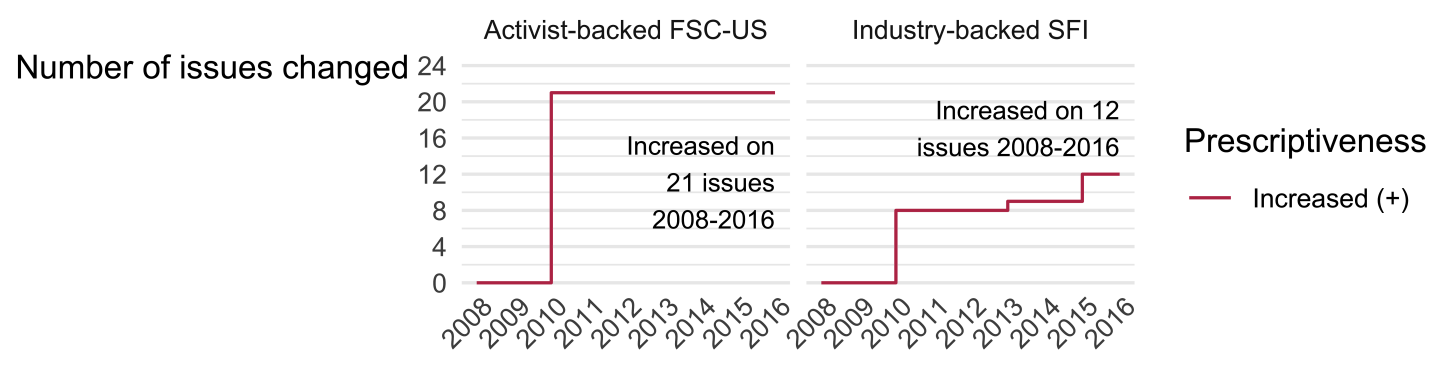


Table 5: Qualitative Levels of Performance Required for Certification

\begin{tabular}{|c|c|c|}
\hline Issue & Activist-backed FSC-US & Industry-backed SFI \\
\hline $\begin{array}{l}\text { Indigenous peoples' } \\
\text { rights }\end{array}$ & $\begin{array}{l}\text { Recognize and uphold rights, customs, } \\
\text { culture, including UNDRIP. No threat } \\
\text { to rights or resources. Free, prior, and } \\
\text { informed consent on public and private } \\
\text { lands. Engage indigenous peoples and } \\
\text { consult with affected groups. } \\
\text { Cooperate to identify and protect } \\
\text { significant sites. Compensate for } \\
\text { indigenous knowledge and utilize as } \\
\text { requested. }\end{array}$ & $\begin{array}{l}\text { A written policy acknowledging a } \\
\text { commitment to recognize and respect } \\
\text { rights. }\end{array}$ \\
\hline $\begin{array}{l}\text { Public Reporting and } \\
\text { Consultation }\end{array}$ & Required on public and private lands. & Required on public lands. \\
\hline $\begin{array}{l}\text { Forest conversion to } \\
\text { non-forest }\end{array}$ & $\begin{array}{l}\text { Prohibited except limited areas where } \\
\text { clear, substantial, additional, secure, } \\
\text { long-term conservation benefits. }\end{array}$ & No specific policy. \\
\hline Old growth forest & $\begin{array}{l}\text { Old growth is normally mapped as } \\
\text { conservation forest. Only restoration } \\
\text { management on public land. Legacy } \\
\text { trees not harvested. Maintain } \\
\text { structure, composition, and processes. } \\
\text { A portion of the forest is restored } \\
\text { where old growth would naturally } \\
\text { occur. }\end{array}$ & $\begin{array}{l}\text { Support and participate in programs } \\
\text { for old growth conservation - no } \\
\text { identification or restoration } \\
\text { requirements. }\end{array}$ \\
\hline Protected areas & $\begin{array}{l}\text { Conserve or restore a representative } \\
\text { area of natural ecosystems. Assess and } \\
\text { maintain environmental values and } \\
\text { necessary conservation measures. }\end{array}$ & No specific policy. \\
\hline $\begin{array}{l}\text { Threatened and } \\
\text { Endangered Species }\end{array}$ & $\begin{array}{l}\text { Survey and report or assume } \\
\text { vulnerable and imperiled species are } \\
\text { present. Maintain habitat \& viable } \\
\text { populations. }\end{array}$ & $\begin{array}{l}\text { Program to protect threatened and } \\
\text { endangered species at known sites. } \\
\text { Protect viable populations of imperiled } \\
\text { species. }\end{array}$ \\
\hline $\begin{array}{l}\text { Workers' right to } \\
\text { organize }\end{array}$ & $\begin{array}{l}\text { Workers are free to associate and } \\
\text { advocate. Develop dispute resolution. }\end{array}$ & Obey laws. Train on worker rights. \\
\hline Wages & $\begin{array}{l}\text { Written commitment to comply with } \\
\text { social law prevailing wage. }\end{array}$ & Train on wage rules. \\
\hline Safety & $\begin{array}{l}\text { Safety guidelines posted. Contracts } \\
\text { include safety. Records kept. }\end{array}$ & $\begin{array}{l}\text { Training on and written commitment } \\
\text { to comply with U.S. Occupational } \\
\text { Safety and Health Administration } \\
\text { requirements. }\end{array}$ \\
\hline
\end{tabular}


Figure 4: Limits on Clearcut Size

\section{Industry-backed SFI}

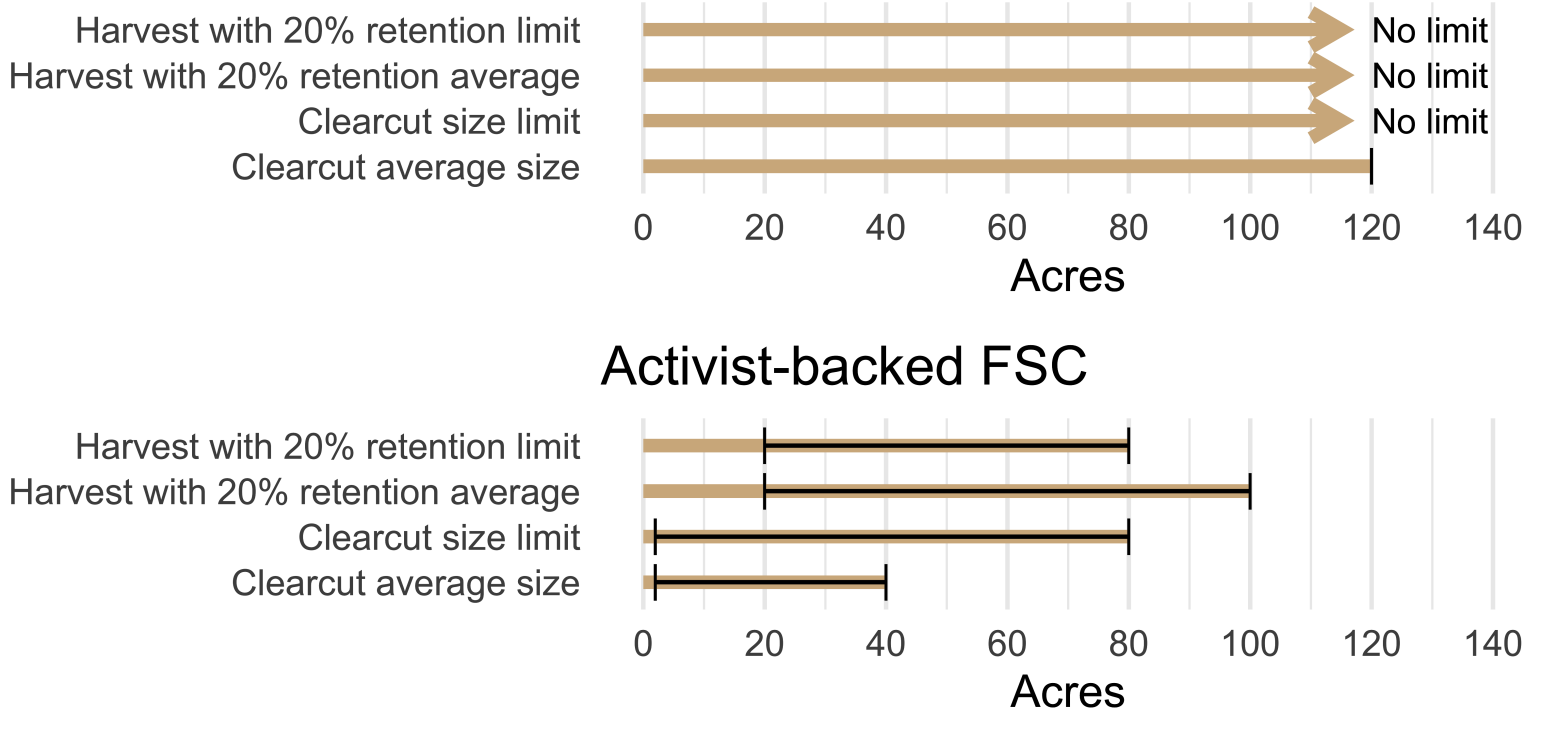

${ }^{*}$ Ranges reflect different maximums for different forest types

made the same year by the FSC-US emphasized conservation-oriented forestry while removing a training requirement.

The bulk of the divergence occurred on ecological requirements like protecting habitats, where the FSC-US became more prescriptive while the SFI stayed constant or, in the case of preserving old-growth forests, decreased in prescriptiveness. Regarding protected areas, the FSC-US continued to require that managers preserve representative samples of habitats, but, since 2010, it also required an assessment of the adequacy of permanent protections. SFI's requirements for protected areas continued to be encompassed mainly by its requirements to protect imperiled species. SFI continued to require plans to identify and protect moderately to highly vulnerable known populations of imperiled or critically imperiled species (designations G1-G2). In contrast, the FSC-US expanded the scope of species requiring protection in 2010 to include natural heritage species and candidate species (designations G1-G3, S1-S3, N1-N3). The FSC-US added requirements to conduct surveys for any at-risk species potentially present or presume that listed or candidate species are present if the forest is in a species' range. For old-growth forests, in 2010, the FSC-US added prescriptive requirements to restore a portion 
Figure 5: Limits on Harvesting Near Streams

Industry-backed SFI \& PEFC

$\begin{array}{ccc}\text { [PEFC Benchmarks] } & \text { All streams } & \text { No buffer ("avoid harm") } \\ \text { SFI (all regions) } & \text { All streams } & \text { No buffer (Follow BMPs, "protect water quality") }\end{array}$

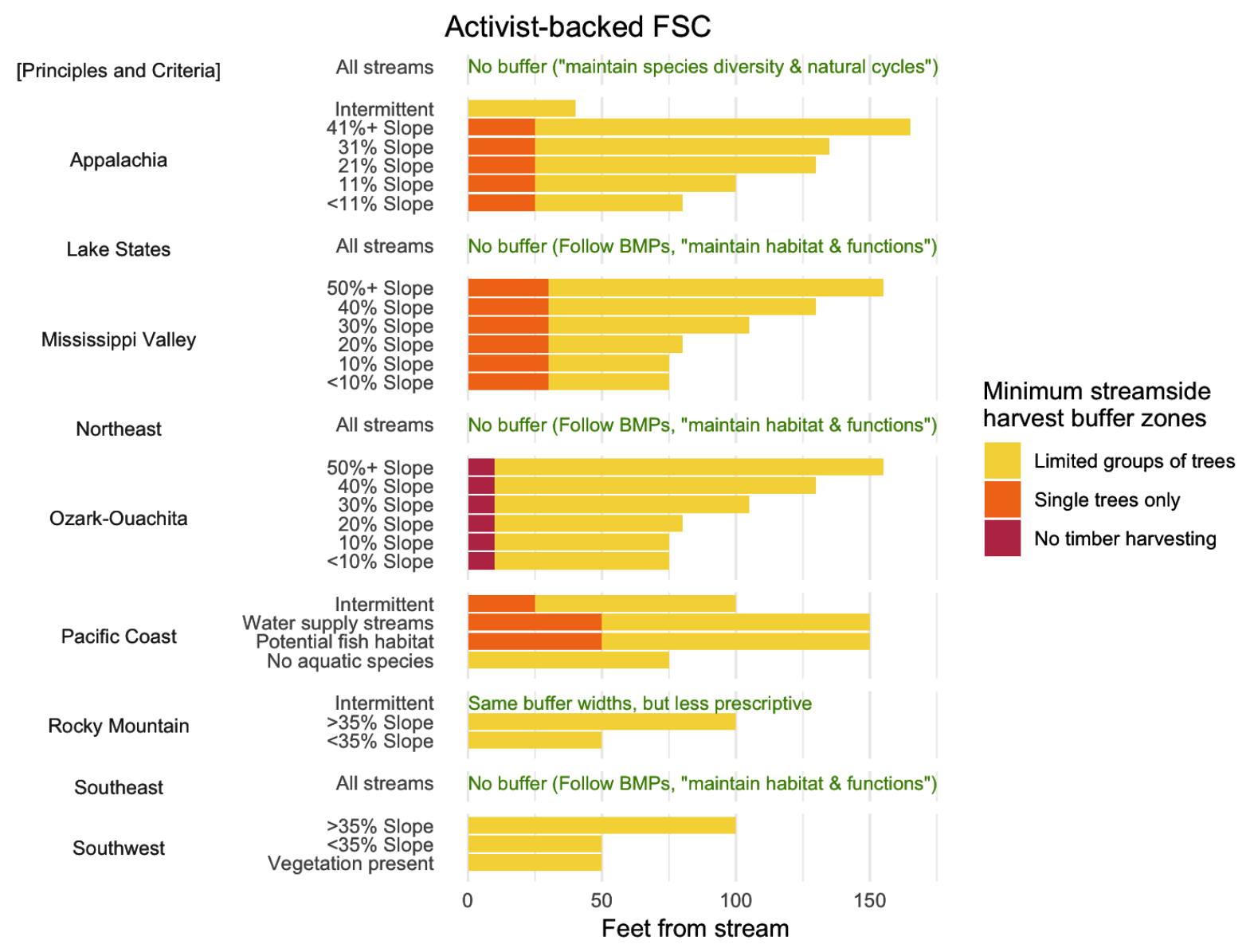


of old-growth forests where they would naturally occur, and it continues to demand protection measures that generally prohibit harvesting. In 2010, SFI removed a requirement to maintain sufficient old-growth acreage to maintain biodiversity, but in 2015 added a requirement to participate in conservation planning.

The FSC-US and SFI's changing requirements to designate and protect conservation areas exemplify their overall upwardly diverging prescriptiveness, with the SFI adding some prescriptive requirements but the FSC-US adding even more prescriptive requirements. In 2010, the SFI added new requirements to collect data on "Forests of Exceptional Conservation Value" (FECV), which we compare with the FSC's requirements for "High Conservation Value Forests" (HCVF). Also, in 2010, the FSC-US added language regarding monitoring and adaptive management of HCVFs. While the acronyms and even the additional language appear similar, the SFI allowed more flexibility in FECV management. HCVFs under the FSC-US required significantly more than baseline practices (Newsom and Hewitt, 2005), while SFI's FECV requirements were criticized for not significantly exceeding legal baselines (state and federal endangered species acts) which already protected threatened and endangered species. The FSC-US then added even more prescriptive requirements requiring certain areas to be designated HCVFs and prescriptive accountability mechanisms for HCVF management.

Summary: The overall pattern for the FSC-US and SFI from 2008 to 2016 was neither convergence to the top nor bottom, but "upward divergence." Each program had distinct areas in which its requirements became more prescriptive. For the FSC, these requirements tended to demand that forest operations "resemble natural processes" and "maintain ecosystem function." Compared to the previous version, this language appeared more frequently and forcefully in the 2010 standard on issues including clearcutting, riparian management, HCVF designations, protected areas, old-growth forests, snags and downed wood, residual trees, genetic diversity, plantations, restoration, natural disturbance, non-timber forest products, soil protection, road building, and management planning. In contrast, the SFI was "most prescriptive" (as prescriptive more than the FSC-US) on issues such as material utilization, 
research, training, education, and public reporting and consultation. The eight key issues on which the SFI increased prescriptiveness in 2010 also reflect the SFI's focus on industry capacity and reputation. These included aesthetics, public reporting, education, training, and utilization.

The 2015 changes to the SFI standard reflect a different tack. In contrast to the previous focus on more "business-friendly" issues related to industry capacity and reputation, the three issues on which the SFI increased prescriptiveness in 2015 reflect social and ecological goals. These include prohibiting the use of certain toxic chemicals, restricting the circumstances under which plantations converted from natural forests can be certified, and requiring a written policy to recognize and respect indigenous rights.

\section{Discussion}

\subsection{Overall Comparison}

By distinguishing different types of stringency, our framework improves upon blunt measures of "high" or "low" based on ambiguous concepts or only a few of the many issues a policy may address.

Overall, our results are consistent with the expectation that activist-backed programs have higher levels of more costly types of stringency. On ecological goals, the FSC-US standard was significantly more stringent than the SFI standard on both scope and prescriptiveness dimensions. On social goals, results are more mixed. On scope, the FSC-US standard protected land tenure and required that local communities benefit from harvesting in ways that were unmatched by SFI's standard. Numerically, FSC-US covered a broader scope of social issues. On prescriptiveness, the contrast was more stark, with the FSC-US standard having significantly more prescriptive requirements on most social issues. On policy settings, the two programs had significant differences. On labor standards and indigenous rights, the FSC-US required higher wages and more attention to rights than did the SFI. In short, by 
the scope of issues addressed, by most qualitative comparisons, and certainly in terms of prescriptiveness, the FSC-US standard was more stringent than the SFI standard on social issues.

On more business-oriented goals such as efficiency (e.g., levels of cut tree utilization), industry capacity (e.g., workforce training and research), and industry reputation (e.g., public education and aesthetics), the overall patterns were largely reversed. SFI was slightly broader in scope (requiring contributions to research where FSC did not), was more prescriptive, and required higher performance levels on many business-friendly issues.

\subsection{Patterns of Change}

In most years between 2008 and 2016, neither the FSC nor the SFI changed on any issue (the center cell in Table 4, "equilibrium").

When they did change, upwardly diverging prescriptiveness was the most frequent pattern. Most changes for both programs occurred in 2010, where the overall pattern was divergence rather than convergence or stability. For all 16 issues on which only the FSC-US added requirements, the FSC-US already had the more prescriptive requirements, and almost all of these additions address ecological problems. Similarly, for three out of the four issues on which only the SFI added requirements, the SFI already had more prescriptive requirements.

The vast majority of changes (21 of 27 issues changed) fit a pattern where one program increased prescriptiveness while the other did not (or in one case, increased to a lesser degree), and the program that increased stringency already had the more prescriptive requirements. On 18 issues, the less prescriptive program stayed the same, leading to upward divergence. On three issues, the less prescriptive program decreased prescriptiveness, leading to opposing divergence (see Table 6).

Convergence was rare. In 2010, upward convergence only occurred when the FSC-US added requirements on the issue of "continual improvement" of harvesting operations, an issue usually associated more with the SFI. This outcome is interesting because scholars generally 
Table 6: Patterns of Change in Prescriptiveness among U.S. Forestry Certification Programs on 48 Key Issues

2010

\begin{tabular}{lccc}
\hline & Converging & Parallell & Diverging \\
\hline Increasing & 1 & 3 & 18 \\
Opposing or Eqilibrium & 0 & 21 & 3 \\
Decreasing & 2 & 0 & 0 \\
\hline
\end{tabular}

2015

\begin{tabular}{lccc}
\hline & Converging & Parallell & Diverging \\
\hline Increasing & 3 & 0 & 0 \\
Opposing or Eqilibrium & 0 & 45 & 0 \\
Decreasing & 0 & 0 & 0 \\
\hline
\end{tabular}

predict that less stringent private regulations will converge toward "benchmark" standards like FSC's (Overdevest, 2005, 2010). Instead, we find the FSC-US ratcheting up prescriptiveness on an issue where its industry-backed competitor had more stringent requirements. Indeed, most studies overlook the possibility that industry-backed standards like the SFI may be more stringent on some issues and thus fail to theorize about dynamics that could cause this. We see downward convergence only on the issues of "community benefits" and "tenure rights," where the more prescriptive FSC-US removed requirements, thus moving closer to SFI.

Parallel change was also rare. An upward parallel change occurred on only three issues in 2010: forest management planning, controlling carbon emissions, and reporting and consultation, where both programs added requirements. We classify the addition of protections for riparian zones by both SFI and FSC-US as another case of upward divergence rather than upward parallel change because the requirements for riparian protection added by the FSC-US were more prescriptive than those added by the SFI. No issues exhibited downward parallel change, as "race to the bottom" theory anticipates.

After the significant revisions of both programs in 2010, only the SFI updated its 
requirements, mostly in 2015. In contrast to the 2010 changes, the pattern in 2015 was a slight upward convergence. SFI increased prescriptiveness on three issues where it did not already have the most prescriptive requirements. While a much smaller scale of change than 2010, this upward convergence is notable because it focuses on regulating toxic chemicals, plantations, and harvesting on tribal lands, which likely have net costs rather than benefits for the industry.

\subsection{IMPLICATIONS FOR THEORY}

Applying our framework to the case of forestry certification reveals how one could reach different conclusions by looking at different dimensions of change. If focusing only on program scope, one would find little support for any theory predicting change- either convergence or divergence. If focusing only on prescriptiveness on ecological issues, one would find divergence, with the activist-backed FSC-US becoming more prescriptive at a faster rate than

the industry-backed SFI. But if focusing only on prescriptiveness on issues related to industry capacity and reputation, one would find the opposite, with the SFI becoming more prescriptive at a faster rate than the FSC-US. While certainly inconsistent with "race-to-the-bottom" theories, the overall upwardly divergent trajectories of the SFI and FSC-US do not exactly fit a "race to the top" (upward parallel) pattern either.

These results are consistent with Hypotheses 1.1, 2.1, and 2.2 outlined above in Section 2.3. We cannot assess Hypothesis 1.2 because neither program changed significantly in policy scope. (Both programs did begin regulating carbon emissions in 2010, but it is unclear if this change in scope is one program reacting to the other or both programs responding to a third causal variable.)

Regarding Hypothesis 1.1. The industry-backed SFI program often contained language similar to that of the activist-backed FSC-US program (i.e., it was similar in scope), but often lacked (costlier) mandatory performance thresholds (i.e., the requirements were less prescriptive). This result suggests that any effort to test theories related to compliance cost 
or differentiation must distinguish between measures of stringency based on policy scope or prescriptiveness. Failing to account for differences in types of regulatory stringency will render empirical findings incomplete at best and misleading at worst.

Consistent with Hypothesis 2.1, the activist-backed FSC-US program was more comprehensive in scope, was more prescriptive, and had higher performance levels on issues that are more costly for firms to address. Conversely, the industry-backed SFI program was more comprehensive in scope, was more prescriptive, and had higher performance levels on issues that create net utility for the industry.

Hypothesis 2.2 posits that differentiation rooted in compliance costs will also explain policy change. This prediction is consistent with changes to the FSC-US and SFI in 2010, but not with changes made by SFI in 2015, where we saw an industry-backed program adding prescriptive requirements on social and ecological issues that are likely to impose costs on producers.

More research is needed to test these and other hypotheses, using similarly precise and comprehensive measures of regulatory stringency in other policy domains. Specifically, while "ratcheting up" theories anticipate the general upward direction we observe, more attention is needed to explain why programs may increase prescriptiveness on different issues, especially for issues on which they already have the more stringent requirements.

\subsection{Industry-Backed Certification Programs as a Form of Collec- TIVE ACtion}

Our finding that the SFI and FSC-US were each more prescriptive and continued to become more prescriptive on qualitatively different issues highlights how industry-backed certification programs can serve their industry in two ways.

First, industry-backed certification programs provide individual firms with a service - a signal of "social responsibility" that requires a credible third party to send. Another way to send such a signal would be to comply with an activist-backed regulation, but this may 
be much more expensive. Hence, industry-backed programs are often created to save firms money by offering a label that sends "green" or "socially responsible" signals in the market without some of the more costly demands of activist-backed programs or public regulations. Such signals rely on perceived, rather than actual, stringency. ${ }^{3}$

Second, industry-backed certification programs provide a mechanism for an industry to improve its collective reputation and capacity by coordinating contributions to collective goods, a common function of industry associations. That the SFI developed more prescriptive standards than the FSC-US on several issues is inconsistent with the predictions that competition between industry-backed and activist-backed competition will lead to a "race to the bottom" on all issues. It is also inconsistent with the prediction that activist-backed standards will be more prescriptive on all issues. However, the substance of these issues suggests that these requirements are not a result of competition with the FSC. Instead, the SFI had the most prescriptive requirements for actions that firms may take anyway-like training workers and maximizing efficiency — or that present collective action problems for the industry - like managing the visual impact of harvesting and sector-level reputation. Likewise, the three issues on which only the SFI changed - maximizing the utilization of cut trees, public education, and worker training - reflect concerns for the efficiency, reputation, and capacity of the forest products industry. Educating the public about forestry and training workers may not exclusively benefit individual firms, but given the broad adoption of SFI certification, such requirements may provide collective benefits for the sector in the form of a positive public image and skilled workforce.

In short, for the handful of issues where the SFI developed more prescriptive requirements than did the FSC-US, SFI requirements tended to focus on actions that firms would likely take in the absence of certification (such as training workers or educating the public) but where certification may provide additional collective benefits by causing them to be more widely adopted. While unforeseen by existing theories, the fact that the SFI is more prescriptive on some issues is unsurprising if these requirements provide net benefits to the sector regardless 
of activist pressures or consumer demands. Disentangling the type of regulatory stringency is thus necessary to assess whether industry-backed programs increasing stringency supports or contradicts broader theories of competition between activist and industry-backed programs.

\section{Conclusion}

Scholars have made substantial progress in developing theories of how economic and political forces shape the substance of private regulations, and how these different requirements then affect levels of adoption and compliance. We have argued that these theories require more attention to the types of policy to which they apply and that testing these theories requires research that measures change across programs and over time. Our framework for measuring regulatory stringency and using longitudinal data to classify patterns of change offers a foundation for further research. The overwhelming failure to do so thus far has hampered the accumulation of knowledge and caused confusion about the potential and limits of private governance. There is no perfect way to compare incommensurate policies. We have nonetheless made our best effort to offer a method to do so. By applying this method, we have systematically quantified differences that can be quantified and described as richly as possible those comparisons that one can only make qualitatively.

Applying our framework to the case of forestry standards in the United States demonstrates the utility of fine-grained analyses concerning regulatory stringency and policy change. Our results show different patterns depending on whether researchers decide to emphasize policy scope, prescriptiveness, or specific policy settings. Attention to all three dimensions of stringency uncovered trends that previous scholarship had missed and which contradict the predictions of several dominant theories.

Previous studies of forest certification illustrate how empirical debates often result from research design choices that capture some patterns but miss others. Some scholars chose a few key issues and found convergence. Others used different issues or measures and did not. Still others made broad generalizations in both directions without specifying a scope of 
policy content or measurement concepts at all. Our integration of both precise and broad measures found that both conclusions were accurate but incomplete. Activist-backed and industry-backed programs converged in policy scope on a few issues, but overall, their scopes have seen little change. Furthermore, we found these programs to have diverged overall on prescriptiveness, because, while both standards "ratcheted up," they did so at different rates and on different policy issues. This deep dive into defining regulatory stringency and policy change in one domain both lays a foundation for scholarship on the causes of public and private regulation in forestry and offers a model for similar research in other policy domains.

Our methodological critique and corrective framework also have practical value. First, the power dynamics among coalitions that promote programs like the FSC or the SFI have created an environment in which competing claims about their requirements and how they have changed causes confusion among potential buyers of certified products. The politics of private regulation revolve around claims about the relative stringency of each program's requirements, "public comparisons that would resolve the debate about whose standards were higher" (Overdevest, 2010). Our framework disentangles abstract notions of "higher" with more concrete and objective ways to measure regulatory stringency. Second, it is impossible to measure the impact of a set of regulatory requirements without disentangling their component parts. Our analysis of written requirements is thus a critical, but often overlooked first step for efforts to assess the effects of these programs on the ground (van der Ven et al., 2018).

Most importantly, our framework and analysis offer a model for careful measurement of policy change as a variable. It is tempting to take shortcuts by making broad generalizations or by selecting what is easy to measure or what others have highlighted. However, if we aim to build testable theories or collect the kinds of evidence needed to test existing theories, we must define policy change in ways that can be applied across programs and over time. Doing so will not only improve the quality of research and theory, it may also uncover entirely new puzzles and insights. 


\section{Notes}

${ }^{1}$ Cashore et al. (2004) found that while environmental groups evaluated the FSC as legitimate for developing wide-ranging and prescriptive standards, private forest owners found the same regulatory approach to be "illegitimate."

${ }^{2}$ While assessing a comprehensive set of issues reduces the risk of omitting key issues on which regulations may vary, it is often time-consuming and costly. Scholars may thus opt for a limited scope, as long as they clearly describe their study's scope relative to the potential set of comparisons. A comprehensive approach is necessary, however, to assess claims about the scope of regulations (such as the hypotheses from section 2.3).

${ }^{3}$ While our framework clarifies many differences in actual stringency between activist- and industry-backed programs, each actor's problem definitions and values will determine the program they prefer. For example, actors prioritize different issues. Some may value actual stringency while others value perceived stringency. Industry-backed programs often address the same issues as activist-backed programs, using language that might imply equivalency in stringency, but which contain substantially fewer prescriptive requirements. Yet seemingly similar looking language can require very different levels of performance. For example, the SFI requirements for "Forests of Exceptional Conservation Value" (FECV) are much less prescriptive than the FSC-US requirements for "High Conservation Value Forests" (HCVF), despite their similar language (also see Figures 5 and 4 and Table 5). The extent to which this helps firms coordinate to maximize the impression of stringency while minimizing the costs of doing so is a question for future research. 


\section{REFERENCES}

Abbott, K. W. and Snidal, D. (2009). The Governance Triangle: Regulatory Standards Institutions and The Shadow of the State. In Mattli, W. and Woods, N., editors, The Politics of Global Regulation. Princeton University Press, Princeton, N.J.

Abbott, K. W. and Snidal, D. (2010). International regulation without international government: Improving IO performance through orchestration. The Review of International Organizations, 5(3):315-344.

Abderrazak, C. and Youssef, A. B. (2009). Multiplicity of eco-labels, competition, and the environment. Journal of Agricultural and Food Industrial Organization, 7(2):1-22.

Atkinson, L. and Rosenthal, S. (2014). Signaling the Green Sell: The Influence of Eco-Label Source, Argument Specificity, and Product Involvement on Consumer Trust. Journal of Advertising, 43(1):33-45.

Auld, G. (2014). Constructing private governance: The rise and evolution of forest, coffee, and fisheries certification. Yale University Press, New Haven.

Bartley, T. (2003). Certifying Forests and Factories: States, Social Movements, and the Rise of Private Regulation in the Apparel and Forest Products Fields. Politics ES Society, 31(3):433-464.

Bartley, T. (2007). Institutional Emergence in an Era of Globalization: The Rise of Transnational Private Regulation of Labor and Environmental Conditions. American Journal of Sociology, 113(2):297-351.

Bartley, T. (2018). Rules Without Rights. Oxford University Press.

Baumgartner, F. R. (2002). Positive and negative feedback in politics. In Baumgartner, F. R. and Jones, B. D., editors, Policy Dynamics. University of Chicago Press, Chicago.

Berger, S. and Dore, R. (1996). National diversity and global capitalism. Cornell University Press.

Bernstein, S. and Cashore, B. (2007). Can non-state global governance be legitimate? An analytical framework. Regulation and Governance, 1(August):347-371.

Bodansky, D. (1999). The Legitimacy of International Governance: A Coming Challenge for International Environmental Law? The American Journal of International Law, 93(3):596.

Botzem, S. and Dobusch, L. (2012). Standardization Cycles: A Process Perspective on the Formation and Diffusion of Transnational Standards. Organization Studies, 33(5-6):737-762.

Bozzi, L., Cashore, B., Levin, K., and McDermott, C. (2012). The Role of Private Voluntary Climate Programs Affecting Forests: Assessing their Direct and Intersecting Effects. In Ronit, K., editor, Business and Climate Policy: The Potentials and Pitfalls of Private Voluntary Programs. United Nations University Press. 
Brunel, C. and Levinson, A. (2016). Measuring the Stringency of Environmental Regulations. Review of Environmental Economics and Policy, 10(1):47-67.

Cashore, B. (1997). Governing Forestry: Environmental Group Influence in British Columbia and the US Pacific Northwest. PhD thesis, University of Toronto.

Cashore, B. (2002). Legitimacy and the Privatization of Environmental Governance: How Non-State Market-Driven (NSMD) Governance Systems Gain Rule-Making Authority. Governance, 15(4):503-529.

Cashore, B., Auld, G., and Newsom, D. (2004). Governing Through Markets: Forest Certification and the Emergence of Non-state Authority. Yale University Press.

Darnall, N., Potoski, M., and Prakash, A. (2010). Sponsorship Matters: Assessing Business Participation in Government- and Industry-Sponsored Voluntary Environmental Programs. Journal of Public Administration Research and Theory, 20(2):283-307.

DeLeon, P. and Rivera, J. E. (2009). Voluntary Environmental Programs : a Policy Perspective. Lexington Books, Lanham.

Delmas, M. and Montiel, I. (2008). The Diffusion of Voluntary International Management Standards: Responsible Care, ISO 9000, and ISO 14001 in the Chemical Industry. Policy Studies Journal, 36(1):65-93.

Djelic, M.-L. and Etchanchu, H. (2017). Contextualizing Corporate Political Responsibilities: Neoliberal CSR in Historical Perspective. Journal of Business Ethics, 142(4):641-661.

Eberlein, B., Abbott, K. W., Black, J., Meidinger, E., and Wood, S. (2014). Transnational business governance interactions: Conceptualization and framework for analysis. Regulation E) Governance, 8(1):1-21.

Fischer, C. and Lyon, T. P. (2014). Competing Environmental Labels. Journal of Economics \& Management Strategy, 23(3):692-716.

Fransen, L. (2011). Why Do Private Governance Organizations Not Converge? A PoliticalInstitutional Analysis of Transnational Labor Standards Regulation. Governance, 24(2):359387.

García-Montiel, E., Cubbage, F., Rojo-Alboreca, A., Lujan-Álvarez, C., Montiel-Antuna, E., and Corral-Rivas, J. (2017). An Analysis of Non-State and State Approaches for Forest Certification in Mexico. Forests, 8(8):290.

Grabosky, P. (2013). Beyond Responsive Regulation: The expanding role of non-state actors in the regulatory process. Regulation \& Governance, 7(1):114-123.

Green, J. F. (2013). Rethinking private authority: Agents and entrepreneurs in global environmental governance. Princeton University Press, Princeton, NJ.

Green, J. F. (2017). Blurred Lines: Public-Private Interactions in Carbon Regulations. International Interactions, 43(1):103-128. 
Green-Pedersen, C. (2007). The Dependent Variable Problem within the Study of Welfare State Retrenchment: Defining the Problem and Looking for Solutions. Journal of Comparative Policy Analysis: Research and Practice, 6(1):3-14.

Gulbrandsen, L. H. (2004). Overlapping Public and Private Governance: Can Forest Certification Fill the Gaps in the Global Forest Regime? Global Environmental Politics, $4(2): 75-99$.

Gulbrandsen, L. H. (2014). Dynamic governance interactions: Evolutionary effects of state responses to non-state certification programs. Regulation $\& 3$ Governance, 8(1):74-92.

Hall, P. A. (1993). Policy Paradigms, Social Learning, and the State: The Case of Economic Policymaking in Britain. Comparative Politics, 25(3):275.

Hansen, E., Fletcher, R., Cashore, B., and McDermott, C. (2006). Forest Certification in North America. Technical report, Oregon State University Extension Service.

Hassel, A. (2008). The Evolution of a Global Labor Governance Regime. Governance, 21(2):231-251.

Heyes, A. and Martin, S. (2017). Social Labeling by Competing NGOs: A Model with Multiple Issues and Entry. Management Science, 63(6):1800-1813.

Howard-Grenville, J., Nash, J., and Coglianese, C. (2008). Constructing the License to Operate: Internal Factors and Their Influence on Corporate Environmental Decisions. Law \& Policy, 30(1):73-107.

Howlett, M. and Cashore, B. (2007). Re-Visiting the New Orthodoxy of Policy Dynamics: The Dependent Variable and Re-Aggregation Problems in the Study of Policy Change. Canadian Political Science Review, 1(2):1-14.

Howlett, M. and Cashore, B. (2014). Conceptualizing Public Policy. Comparative Policy Studies: Conceptual and Methodological Challenges, pages 17-33.

Hsueh, L. and Prakash, A. (2012). Incentivizing self-regulation: Federal vs. state-level voluntary programs in US climate change policies. Regulation 83 Governance, 6(4):445-473.

Hudson, I. and Hudson, M. (2003). Removing the Veil?: Commodity Fetishism, Fair Trade, and the Environment. Organization \&5 Environment, 16(4):413-430.

Judge-Lord, D. (2013). Mechanisms of Policy Feedback: Interactions among Regulations and Public Investments in US Farm and Forest Politics. Master's thesis, Yale University.

Kollman, K. and Prakash, A. (2001). Green by Choice? Cross-National Variations in Firms' Responses to EMS-Based Environmental Regimes. World Politics, 53:399-430.

LeBaron, G. and Burgoon, B. (2018). Explaining Patterns of Labor Protection and Exploitation in the Global Tea Supply Chain: Evidence from India. 
Li, Y. and van 't Veld, K. (2015). Green, greener, greenest: Eco-label gradation and competition. Journal of Environmental Economics and Management, 72(C):164-176.

Loconto, A. and Fouilleux, E. (2014). Politics of private regulation: ISEAL and the shaping of transnational sustainability governance. Regulation \&6 Governance, 8(2):166-185.

Lyon, T. P. and Maxwell, J. W. (2008). Corporate Social Responsibility and the Environment: A Theoretical Perspective. Review of Environmental Economics and Policy, 2(2):240-260.

Maxwell, J. W., Lyon, T. P., and Hackett, S. C. (2000). Self-Regulation and Social Welfare: The Political Economy of Corporate Environmentalism. The Journal of Law and Economics, 43(2):583-618.

McDermott, C. (2012). Trust, Legitimacy and Power in Forest Certification: A case study of the FSC in British Columbia. Geoforum, 43:643-644.

McDermott, C., Cashore, B., and Kanowski, P. (2010). Global Environmental Forest Policies: An International Comparison. Earthscan, London.

Meidinger, E. (2003). Forest Certification as Environmental Law Making by Global Civil Society. In Meidinger, E., Elliot, C., and G, O., editors, Social and Political Dimensions of Forest Certification, pages 293-329. Forstbuch: Remegen-Oberwinter.

Mills, R. W. (2016). The interaction of private and public regulatory governance: The case of association-led voluntary aviation safety programs. Policy and Society, 35(1):43-55.

Moore, S. E., Cubbage, F., and Eicheldinger, C. (2012). Impacts of Forest Stewardship Council (FSC) and Sustainable Forestry Initiative (SFI) Forest Certification in North America. Journal of Forestry, 110(2):79-88.

Newsom, D. and Hewitt, D. (2005). The Global Impacts of SmartWood Certification. Technical report, Rainforest Alliance.

Overdevest, C. (2005). Treadmill Politics, Information Politics, and Public Policy. Organization \& Environment, 18(1):72-90.

Overdevest, C. (2010). Comparing forest certification schemes: the case of ratcheting standards in the forest sector. Socio-Economic Review, 8(1):47-76.

Overdevest, C. and Zeitlin, J. (2014). Assembling an experimentalist regime: Transnational governance interactions in the forest sector. Regulation $\&$ Governance, 8(1):22-48.

Poret, S. (2016). Label Battles: Competition among NGOs as Standard Setters.

Porter, T. (2014). Technical systems and the architecture of transnational business governance interactions. Regulation $\&$ Governance, 8(1):110-125.

Potoski, M. and Prakash, A. (2005). Green clubs and voluntary governance: ISO 14001 and firms' regulatory compliance. American Journal of Political Science, 49(2):235-248. 
Prado, A. M. (2013). Competition Among Self-Regulatory Institutions. Business $\& 3$ Society, 52(4):686-707.

Prakash, A. (2000). Greening of the Firm: The Politics of Corporate Environmentalism. Cambridge University Press, Cambridge.

Prakash, A. and Potoski, M. (2007). Collective Action through Voluntary Environmental Programs: A Club Theory Perspective. Policy Studies Journal, 35(4):773-792.

Schmitz, E. A., Baum, M., Huett, P., and Kabst, R. (2017). The Contextual Role of Regulatory Stakeholder Pressure in Proactive Environmental Strategies: An Empirical Test of Competing Theoretical Perspectives. Organization \& Environment, page 108602661774599.

Smith, T. M. and Fischlein, M. (2010). Rival private governance networks: Competing to define the rules of sustainability performance. Global Environmental Change, 20(3):511-522.

Tigar, J. S. (2017). Resolute Forest Products, Inc. et al. v. Greenpeace International et al.

van der Ven, H. (2015). Correlates of rigorous and credible transnational governance: A cross-sectoral analysis of best practice compliance in eco-labeling. Regulation $\& 3$ Governance, 9(3):276-293.

van der Ven, H., Rothacker, C., and Cashore, B. (2018). More Eco-Labels but Fewer Forests: Lessons from Non-State Market Driven Governance in the Soy, Palm Oil, and Cocoa Sectors.

Vince, J. and Haward, M. (2017). Hybrid governance of aquaculture: Opportunities and challenges. Journal of Environmental Management, 201:138-144.

Vogel, D. (1995). Trading Up: Consumer and environmental regulation in a global economy. Harvard University Press, Cambridge, MA.

Weimer, D. L. (2006). The Puzzle of Private Rulemaking: Expertise, Flexibility, and Blame Avoidance in U.S. Regulation. Public Administration Review, 66(4):569-582. 